\title{
WestVirginiaUniversity
}

THE RESEARCH REPOSITORY @ WVU

Graduate Theses, Dissertations, and Problem Reports

2017

\section{Removal of Zinc lons from Model Wastewater by Electrocoagulation}

Xiujuan Chen

Follow this and additional works at: https://researchrepository.wvu.edu/etd

\section{Recommended Citation}

Chen, Xiujuan, "Removal of Zinc Ions from Model Wastewater by Electrocoagulation" (2017). Graduate Theses, Dissertations, and Problem Reports. 5352.

https://researchrepository.wvu.edu/etd/5352

This Thesis is protected by copyright and/or related rights. It has been brought to you by the The Research Repository @ WVU with permission from the rights-holder(s). You are free to use this Thesis in any way that is permitted by the copyright and related rights legislation that applies to your use. For other uses you must obtain permission from the rights-holder(s) directly, unless additional rights are indicated by a Creative Commons license in the record and/ or on the work itself. This Thesis has been accepted for inclusion in WVU Graduate Theses, Dissertations, and Problem Reports collection by an authorized administrator of The Research Repository @ WVU. For more information, please contact researchrepository@mail.wvu.edu. 


\title{
Removal of Zinc Ions from Model Wastewater by Electrocoagulation
}

\author{
Xiujuan Chen \\ Thesis submitted to \\ Benjamin M. Statler College of Engineering and Mineral Resources \\ at West Virginia University \\ in partial fulfillment of the requirements \\ for the degree of \\ Master of Science in \\ Material Science and Engineering
}

\author{
Xingbo Liu, Ph.D., Chairperson and Advisor \\ Konstantinos A. Sierros, Ph.D. \\ Jason P. Trembly, Ph.D. \\ Material Science and Engineering Program \\ Department of Mechanical and Aerospace Engineering \\ Morgantown, West Virginia \\ 2017
}

Keywords: Wastewater treatment, metals removal, electrocoagulation, Al electrodes

Copyright 2017, Xiujuan Chen 


\section{Abstract \\ Removal of Zinc Ions from Model Wastewater by Electrocoagulation Xiujuan Chen}

This study has investigated the removal of zinc ions from the synthetic wastewater models by electrocoagulation (EC) with aluminum for both cathode and anode. The results showed that EC process had a great removal when it comes to zinc contaminated water. The effects of parameters on the EC performance have been systematically investigated, such as solution conductivity, electrode spacing, initial $\mathrm{pH}$, current density and initial zinc concentration. Since the wastewater in real situations usually contains several types of metals, a series of mixed cases were also studied in this work.

The results indicated that current density is critical to EC performance, in terms of the removal efficiency and energy consumption. The basic conductivity of the solution is required to decrease the EC voltage. It was demonstrated that the neutral $\mathrm{pH}$ is favorable for zinc removal by EC process, while the effect of electrode spacing on EC performance was not significant in this case. With a relatively low energy consumption of $0.35 \mathrm{kWh} / \mathrm{m}^{3}$, more than $99.5 \%$ of zinc ions were removed from the synthetic wastewater (zinc concentration $50 \mathrm{mg} / \mathrm{L}$ ) within $20 \mathrm{~min}$. Later with an energy consumption of $0.88 \mathrm{kWh} / \mathrm{m}^{3}$, highly similar removal efficiency has been achieved at zinc concentration of $250 \mathrm{mg} / \mathrm{L}$ at EC time of 50 minutes.

The kinetic study for zinc removal was performed to describe the adsorption system during EC process. The results show that the removal of zinc ions by EC process follows the first-order model with current-dependent parameters. Additionally, the removal of zinc ions fitted well with the first order model at related low initial concentration, and fitted well with the pseudo-first order model at high initial concentrations. Different mechanisms of zinc removal were implied by comparing the results of the low initial concentration $(\leq 250 \mathrm{mg} / \mathrm{L})$ and the high one $(\geq 500 \mathrm{mg} / \mathrm{L})$. It was reasonable to conclude that, beside the co-precipitation effect of the aluminum hydroxides coagulants, the reduction of zinc ions at the cathode also contributed to the zinc removal, especially at a high initial concentration. The different removal pathways of metal ions usually exist at high initial concentrations of metal ions and alkaline $\mathrm{pH}$ medium. 


\section{Acknowledgement}

First of all, I would like to thank my advisor Dr. Xingbo Liu for his continuous and careful guidance during my last two years here at West Virginia University. Without his effort, I could not have come so far. I would like to thank my committee members, Dr. Konstantinos A. Sierros and Dr. Jason P. Trembly, for their time to improve my research. Thank Dr. Weiqiang Ding, Dr. Qiang Wang and Dr. Redigolo from WVU Shared Facilities, Ms. Gabriela Perhinschi from NRCCE, for helping with the testing and analysis. Thank the cheerful members in Dr. Liu's research group, Dr. Wenyuan Li, Dr. Greg Collins, Bo Guan, Meng Yao, Panpan Ren, Shanshan $\mathrm{Hu}$, Zhipeng Zeng, Haiyang Li, He Qi and Nan Zhang, who always inspire and encourage me to go further. At the end, I would like to thank my husband Changle Jiang and my entire family. Without their support, I would not be able to finish my study here at Morgantown. 


\section{Table of Contents}

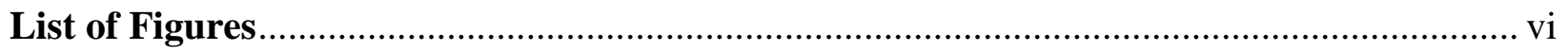

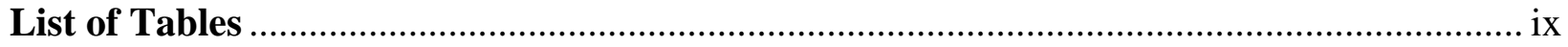

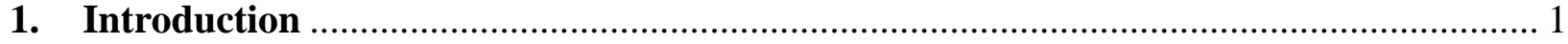

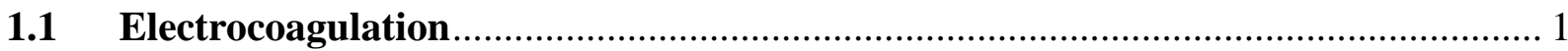

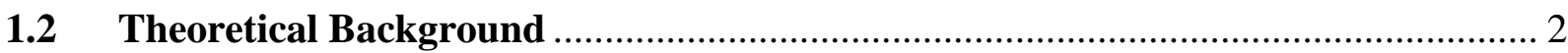

1.2.1 General Theory of Electrocoagulation ...................................................... 3

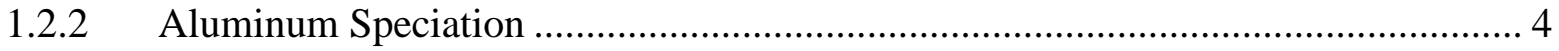

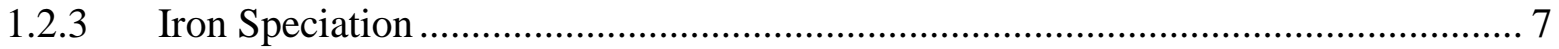

1.2.4 Key Parameters for EC Process ..................................................................... 9

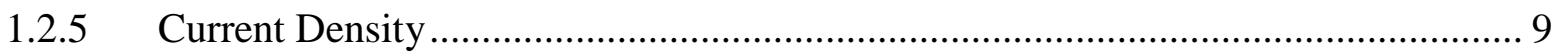

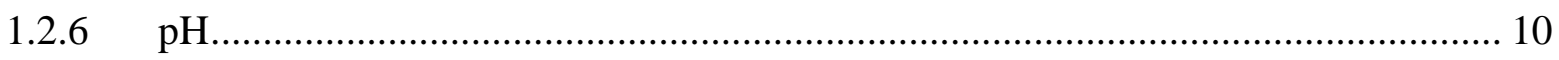

1.3 Comparison of Electrocoagulation and Chemical Coagulation............................ 10

1.4 Advantages and disadvantages of electrocoagulation ....................................... 11

1.5 Electrocoagulation for Heavy Metal Removal............................................... 13

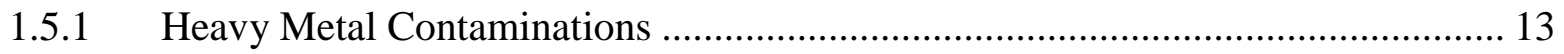

1.5.2 Current Technology for Heavy Metals Removal ............................................... 13

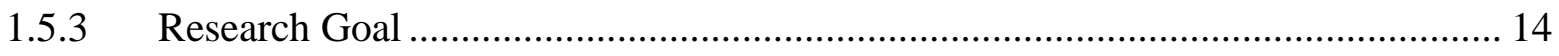

2. Experimental Sections and Characterizations................................................ 15

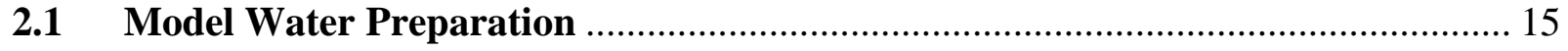

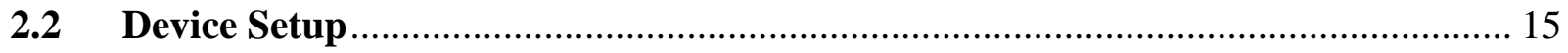

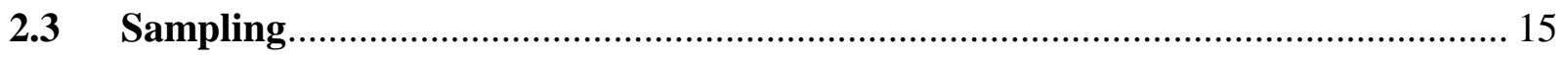

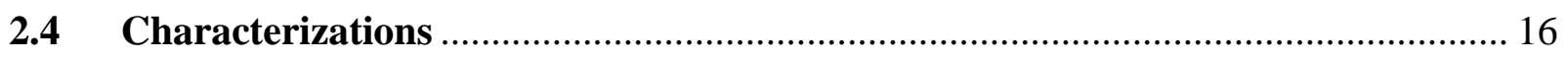

3. Effect of Reactor and Water Matrix Parameters on Metal Ions Removal .................. 18

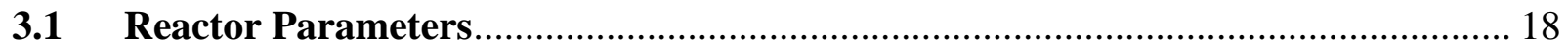

3.1.1 Effect of Current Density on EC Performance ................................................ 18

3.1.2 Effect of Electrode Spacing on EC Performance............................................ 23

3.1.3 Effect of Electrodes Arrangement on EC Performance ......................................... 24

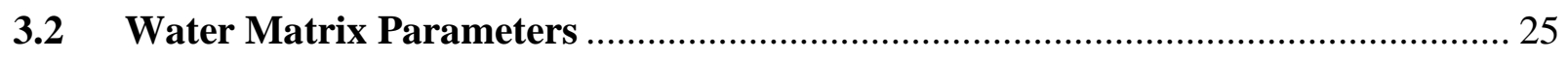

3.2.1 Effect of Solution Conductivity on EC Performance ...................................... 25

3.2.2 Effect of Initial Solution $\mathrm{pH}$ on EC Performance ............................................. 27

3.2.3 Effect of Initial Concentration of Zinc on EC Performance ............................... 28 


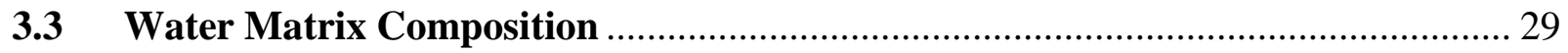

3.3.1 Removal of Strontium by EC ...................................................................... 29

3.3.2 Mixed Contaminant Removal (Zn, Cu, Fe, Mn, Mg, Ca, Ba and Sr)................. 32

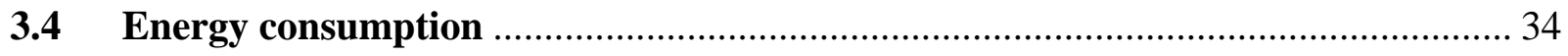

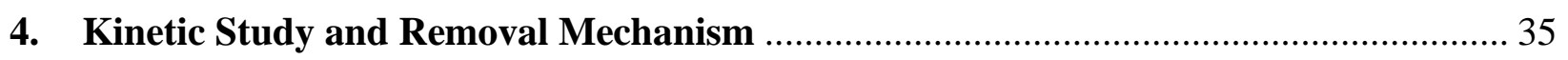

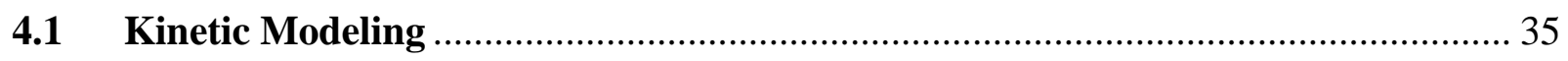

4.1.1 Kinetic Modelling at Different Current Densities ............................................ 36

4.1.2 Kinetic Modelling at Different Initial Concentrations ....................................... 38

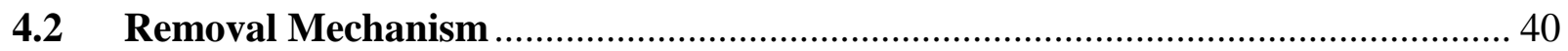

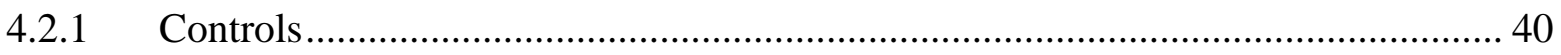

4.2.2 Characteristic of the By-products of EC Process.............................................. 41

4.2.3 Possible Removal Path of Zinc Ions by EC Treatment..................................... 45

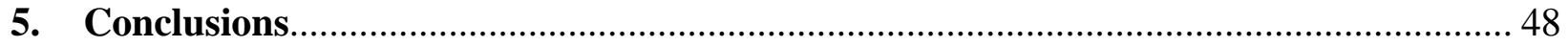

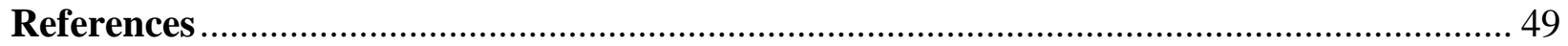




\section{List of Figures}

Figure 1.1 Classification of typical operations in wastewater treatment plants (Moussa et al.

2017).

Figure 1.2 E-pH diagrams of: a) Iron and b) Aluminum at $25^{\circ} \mathrm{C}$ (Vepsäläinen 2012). 6

Figure 2.1 Schematic diagram of experimental setup. 16

Figure 3.1 The time profiles at different current densities: (a) $\mathrm{pH}$; (b) residual aluminum concentration; and (c) zinc removal efficiency. (d) Evolution of zinc removal efficiency versus charge loading. $\mathrm{C}_{0}=50 \mathrm{mg} / \mathrm{L}, \sigma=9.72 \mathrm{mS} / \mathrm{cm}, \mathrm{d}=1.0 \mathrm{~cm}$.

Figure 3.2: Concentrations of monomeric hydrolysis products of Al(III) in equilibrium with the amorphous hydroxides, at zero ionic strength and $25^{\circ} \mathrm{C}$ (Duan, J et al. 2003).

Figure 3.3 Influence of current density on bubble generation during EC: (a) $2.1 \mathrm{~mA} / \mathrm{cm}^{2}$; (b) 12.5 $\mathrm{mA} / \mathrm{cm}^{2}$

Figure 3.4 Effect of electrode spacing on zinc removal performance. $\mathrm{C}_{0}=50 \mathrm{mg} / \mathrm{L}, \mathrm{CD}=4.2$ $\mathrm{mA} / \mathrm{cm}^{2}, \sigma=9.72 \mathrm{mS} / \mathrm{cm}, \mathrm{t}=15 \mathrm{~min}, \mathrm{pH}_{\text {initial }}=5.25 \pm 0.03$. 23

Figure 3.5 Sketch of the EC systems with: (a) two aluminum electrodes and (b) dipolar electrodes. Electrode spacing is $1.0 \mathrm{~cm}$ in both systems.

Figure 3.6 Effect of electrodes arrangement on removal of zinc with EC time. 25

Figure 3.7 Variation of electrolysis voltage during the EC process. $\mathrm{C}_{0}=50 \mathrm{mg} / \mathrm{L}, \mathrm{CD}=4.2$ $\mathrm{mA} / \mathrm{cm}^{2}, \mathrm{~d}=3.0 \mathrm{~cm}, \mathrm{t}=15 \mathrm{~min}, \mathrm{pH}_{\text {initial }}=5.25 \pm 0.03$. 26

Figure 3.8 Effect of solution conductivity on removal efficiency of zinc. $\mathrm{C}_{0}=50 \mathrm{mg} / \mathrm{L}, \mathrm{CD}=4.2$ $\mathrm{mA} / \mathrm{cm}^{2}, \mathrm{~d}=3.0 \mathrm{~cm}, \mathrm{t}=15 \mathrm{~min}, \mathrm{pH}_{\text {initial }}=5.25 \pm 0.03$ 27

Figure 3.9 Effect of initial $\mathrm{pH}$ on the zinc removal efficiency. $\mathrm{C}_{0}=50 \mathrm{mg} / \mathrm{L}, \mathrm{CD}=4.2 \mathrm{~mA} / \mathrm{cm}^{2}$, $\sigma=9.72 \mathrm{mS} / \mathrm{cm}, \mathrm{d}=1.0 \mathrm{~cm}, \mathrm{t}=15 \mathrm{~min}$. 28 
Figure 3.10 Effect of initial concentration on removal of zinc ions during EC process. Initial concentrations were 50,100, 250, 500, 1,000 and 2,000 mg/L. CD =8.3 mA/cm², $\sigma=9.7$ $\mathrm{mS} / \mathrm{cm}, \mathrm{d}=1.0 \mathrm{~cm}$.

Figure 3.11 Effect of current density on the removal of strontium ions. Applied current: 0.05 $0.3 \mathrm{~A}, \mathrm{C}_{0}=10 \mathrm{mg} / \mathrm{L}, \sigma=9.72 \mathrm{mS} / \mathrm{cm}, \mathrm{d}=1.0 \mathrm{~cm}, \mathrm{t}=60 \mathrm{~min}$.

Figure 3.12 Effect of initial $\mathrm{pH}$ on the removal of strontium ions. $\mathrm{CD}=2.1 \mathrm{~mA} / \mathrm{cm}^{2}, \mathrm{C}_{0}=10$ $\mathrm{mg} / \mathrm{L}, \mathrm{d}=1.0 \mathrm{~cm}, \mathrm{t}=30 \mathrm{~min}$. 31

Figure 3.13 Effect of electrode spacing on the removal of strontium ions. $\mathrm{CD}=8.3 \mathrm{~mA} / \mathrm{cm}^{2}, \mathrm{C}_{0}$ $=10 \mathrm{mg} / \mathrm{L}, \sigma=9.72 \mathrm{mS} / \mathrm{cm}, \mathrm{t}=30 \mathrm{~min}$. 31

Figure 3.14 Removal efficiency of $\mathrm{Fe}, \mathrm{Cu}, \mathrm{Zn}$, and $\mathrm{Mn}$ ions during EC with model wastewater M-A. $\mathrm{CD}=2.1 \mathrm{~mA} / \mathrm{cm}^{2}, \mathrm{pH}_{\text {initial }}=4.0$. 33

Figure 3.15 Evolution of metals removal efficiency versus EC time during EC process with model wastewater M-B. $\mathrm{CD}=4.2 \mathrm{~mA} / \mathrm{cm}^{2}$.

Figure 3.16 Removed $\mathrm{Mg}, \mathrm{Ca}, \mathrm{Sr}$ and $\mathrm{Ba}$ ions after 30 min EC process with model wastewater $\mathrm{M}-\mathrm{C}$ at different current densities. 34

Figure 3.17 Variation of energy consumption (bar graph) and required EC time (line graph) as a function of current densities for two levels of removal percentages 95-97\% and 99.5-100\%. $\mathrm{C}_{0}=50 \mathrm{mg} / \mathrm{L}$. 35

Figure 4.1 Variation of residual zinc concentrations during EC process at different current densities. The solid lines are fitted curves based on first-order model. 38

Figure 4.2 Variation of both experimental and first-order concentrations versus time at different initial concentrations. The solid lines are fitted curves based on first-order model (at 50, 100 and $250 \mathrm{mg} / \mathrm{L}$ ) and pseudo first-order model (at 500, 1000 and $2000 \mathrm{mg} / \mathrm{L}$ ).

Figure 4.3 Schematic diagrams of control experimental setup: (a) aluminum anode, (b) carbon anode, (c) carbon anode, in the presence of $\mathrm{Al}^{3+} . \mathrm{C}_{0}=250 \mathrm{mg} / \mathrm{L}, \mathrm{CD}=8.3 \mathrm{~mA} / \mathrm{cm}^{2}, \mathrm{~d}=1.0$ $\mathrm{cm}$. 41

Figure 4.4 Schematic diagram of products produced during EC process. 42 
Figure 4.5 SEM and EDX results of the precipitation. Experiment carried out with zinc concentration of $500 \mathrm{mg} / \mathrm{L}$, at current density of $8.3 \mathrm{~mA} / \mathrm{cm}^{2}$ and $\mathrm{EC}$ time of $60 \mathrm{~min} . \ldots \ldots .43$

Figure 4.6 SEM and EDX results of the deposition obtained at cathode surface...................... 44

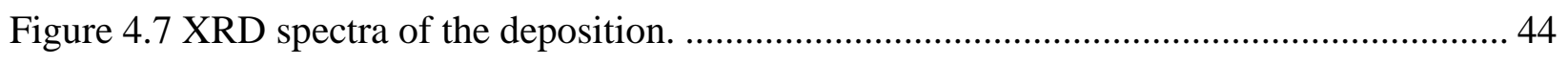

Figure 4.8 XPS spectra of the deposition: (a) full spectrum; (b) Zn 2p................................. 45

Figure 4.9 Schematic diagram of the possible removal pathways of zinc ions during EC process. 


\section{List of Tables}

Table 3.1 Mixed contaminant and concentrations in multi-metal system.

32

Table 4.1 The kinetic parameters for first-order and pseudo-first order model at different current densities.

Table 4.2 The kinetic parameters for first-order and pseudo-first order model at different initial concentrations

Table 4.3 The corresponding results obtained by the control experiments.

Table 4.4 ICP results of the precipitation.

Table 4.5 Possible removal path for zinc ions. 45 


\section{Introduction}

\subsection{Electrocoagulation}

Scarcity of fresh water has become one of the biggest challenges for human society. As the population grows, the fresh water consumption increases generally. Besides, the growth of industrialization not only causes rapid consumption of the limited water sources, but also seriously impacts the drinkable water due to the direct discharge of wastewater without any treatment. Therefore, the effective and efficient wastewater treatment technologies are highly demanded. Those technologies are also necessary to be further improved to reduce water pollution and maintain water quality.
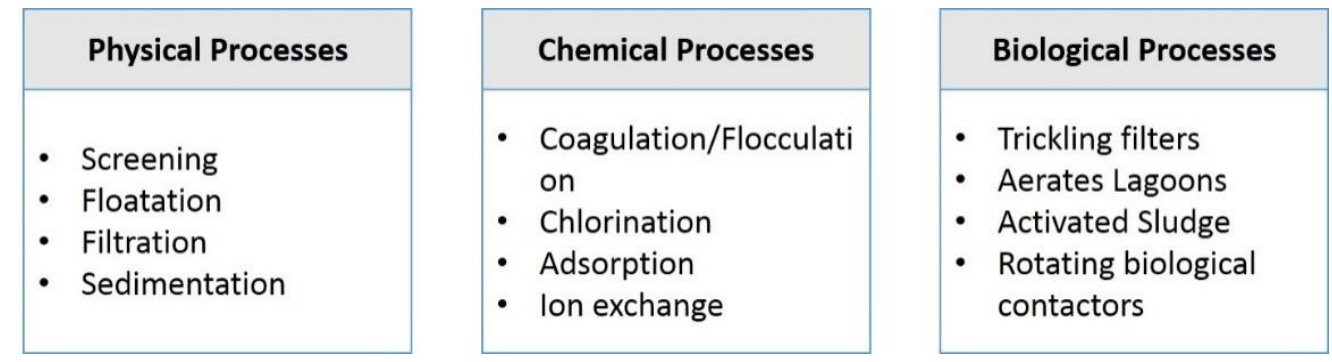

Figure 1.1 Classification of typical operations in wastewater treatment plants (Moussa et al. 2017).

Many typical techniques have been applied in variable treatment cases, such as precipitation, adsorption, filtration, ion-exchange, electrodialysis and membrane separation. These methods could be categorized into three major groups: physical, chemical and biological processes (Kurniawan et al. 2006; Moussa et al. 2017). Figure 1.1 summarizes the typical operations from each category. The treatment methods section not only depends on the pollutants contained in the treated wastewater, such as organic or inorganic constituents, but also relates to the source of the pollutants, for instance urban, industrial and agricultural wastewater, even the associated areas of intensive industry like power plant, steel mill or coal mines. The physical treatments like floatation 
and filtration are commonly used as required procedures for the water purification systems. Pure physical separation could be used to remove pollutants without changing the chemical properties of the treated water. Chemical coagulation is considered as an applicable and effective approach to remove pollutants. The main function is to precipitate the pollutants through the colloidal reaction between pollutants and the added chemicals. The required chemicals include hydroxides (provide hydroxyl ions), iron and aluminum salts (form chemical coagulants). However, the common chemical precipitation generally induce a secondary pollution and plenty of sludge to the water due to the chemical additives. Therefore, it is quite necessary to develop the other lower cost and more effective approaches to avoid secondary pollution.

Electrocoagulation (EC) has been suggested as a promising alternative to chemical coagulation. It has been successfully used to remove a wide range of pollutants (Emamjomeh and Sivakumar 2009). With this technology, the coagulants continuously formed in-situ by dissolution of metal at the anode with simultaneous generation of hydroxide ions at the cathode. Additionally, the hydrogen evolution that occurred together with generation of hydroxide ions at cathode as a beneficial side reaction can promote the separation of flocculated material from the water. The benefits from using EC includes higher effectiveness, energy efficiency and environmental compatibility. EC is a complicated process based on multiple mechanisms of removing metal contamination. It is generally considered as a combination of three major technical fields, electrochemistry, coagulation and flotation. Many have reported that EC was successful on treating wastewater with high removal efficiency and among those studies, the influence of operational parameters on the efficiency is always considered pivotal.

\subsection{Theoretical Background}

Electrocoagulation is an advanced technology which combines three main branches mentioned previously. Those techniques were studied both extensively and separately. Since multiple chemical reactions and physical changes take place simultaneously during the EC process, it is generally impossible to describe the complex and interactions behind the mechanism of EC. Therefore, only major reactions and critical side reactions will be discussed in this part. 


\subsubsection{General Theory of Electrocoagulation}

The basic EC reactor is fabricated by setting up an electrolytic cell with metal anode and cathode both which are immersed in untreated water. A DC or AC power is applied to conduct the cell. Some has reported that inert cathodes were adopted as counter electrodes in the system. During the EC process, the coagulant species are generated in-situ by metal cations from the electrodissolution of sacrificial anode and hydroxide ions from the water electrolysis at cathode. The main reactions can be summarized as follows:

At the anode, metal electrode is oxidized into cations.

$\mathrm{M}(\mathrm{s}) \rightarrow \mathrm{M}^{\mathrm{n}+}(\mathrm{aq})+\mathrm{ne}^{-} \quad($ Eq. 1$)$

In this equation, $M$ is the metal used as anode. Iron and Aluminum are the most extensively used metals for anode and cathode electrodes in EC process. $n$ is the electrons transferred in the anode per mole metal.

At the cathode, water electrolysis produces hydroxyl ions.

$\mathrm{nH}_{2} \mathrm{O}(\mathrm{aq})+\mathrm{ne}^{-} \rightarrow(\mathrm{n} / 2) \mathrm{H}_{2}(\mathrm{~g})+\mathrm{nOH}^{-}(\mathrm{aq}) \quad$ (Eq. 2)

The metal cations combine with hydroxyl ions to form hydroxide flocs (Eq. 3), which serve as the coagulant agents that can precipitate several wastewater pollutants.

$\mathrm{M}(\mathrm{aq})^{\mathrm{n}+}+\mathrm{nOH}^{-}(\mathrm{aq}) \rightarrow \mathrm{M}(\mathrm{OH}) \mathrm{n}(\mathrm{s}) \quad($ Eq. 3)

Overall reactions: $\mathrm{M}(\mathrm{s})+\mathrm{nH}_{2} \mathrm{O}(\mathrm{aq}) \rightarrow \mathrm{M}(\mathrm{OH}) \mathrm{n}(\mathrm{s})+(\mathrm{n} / 2) \mathrm{H}_{2}(\mathrm{~g})$

It should be noted that the oxygen gas that generated simultaneously with hydroxide ions at cathode assists the separation of pollutants and water by bringing the flocculated particles to the water surface and providing them with additional buoyancy.

In addition to the above main reactions, there are some side reaction can also take place in the EC process. Two notable secondary reactions are the oxygen evolution at anode and chemical 
dissolution of electrodes. Both significantly affect the metal cations generation during EC process. The amount of metal actions dissolved from anode follows Faraday's law:

$m=\frac{I t M_{w}}{z F} \quad($ Eq. 5)

where $I$ is the current (A); $t$ is the operation time (s); $M_{w}$ is the molecular weight $(\mathrm{g} / \mathrm{mol})$ of the metal used as anode electrode; $z$ is the number of electrons transferred in the oxidation /reduction reaction $\left(2\right.$ for $\mathrm{Fe}^{2+}, 3$ for $\mathrm{Fe}^{3+}$ and $\left.\mathrm{Al}^{3+}\right) ; F$ is the Faraday's constant $(98,485 \mathrm{C} / \mathrm{mol})$; and $m$ is the quantity of electrode material dissolved from the anode $(\mathrm{g})$.

In some cases, the actual anode dissolution does not fit well with Faraday's law due to the side reactions that occurs at the anode. Some researchers suggested the evolution of oxygen by water oxidation might take place at high anodic potential (Heidmann and Calmano 2008a)

$2 \mathrm{H}_{2} \mathrm{O} \rightarrow \mathrm{O}_{2}(\mathrm{~g})+4 \mathrm{H}^{+}+4 \mathrm{e}^{-} \quad$ (Eq. 6)

At relative higher voltage, the oxygen generation will be enhanced, which can compete current with anode dissolution at the anode and lead to the lower Faraday efficiency of the EC process (Canizares et al. 2005). On the other hand, the simultaneously generated $\mathrm{H}^{+}$will consume $\mathrm{OH}^{-}$ produced at the cathode. Therefore, such secondary reaction is considered to be not favorable for the EC performance.

Several researches have reported the amount of metal cations which generated during electrocoagulation process exceeds that theoretically determined by Faraday's law. This situation is frequent with Aluminum electrode. Despite of the anode dissolution, it was found that the Aluminum also released from the cathode due to the "chemically" attack of aluminum in alkaline media, when the local $\mathrm{pH}$ on the surface of the cathode increases due to the formation of hydroxyl ions (Mouedhen et al. 2008; Picard et al. 2000).

\subsubsection{Aluminum Speciation}

Aluminum and iron are the most extensive electrode materials used in electrocoagulation because these materials are widely considered to be available, low-cost, non-toxic and reliable. With the 
iron and aluminum E-pH diagrams (Figure 1.2, 1.3), the thermodynamically stable compounds of iron and aluminum could be estimated at different conditions. For aluminum electrode, only trivalent $\mathrm{Al}$ (III) cations generates by the electro-dissolution of anode. The resulted $\mathrm{Al}^{3+}$ ions immediately undergo a series spontaneous hydrolysis reactions depending on the $\mathrm{pH}$ of the solution to form corresponding monomeric and polymeric species.

$$
\begin{aligned}
& \mathrm{Al}^{3+}+\mathrm{H}_{2} \mathrm{O} \rightarrow \mathrm{Al}(\mathrm{OH})^{2+}+\mathrm{H}^{+} \\
& \mathrm{Al}(\mathrm{OH})^{2+}+\mathrm{H}_{2} \mathrm{O} \rightarrow \mathrm{Al}(\mathrm{OH})^{2+}+\mathrm{H}^{+} \\
& \mathrm{Al}(\mathrm{OH})^{2+}+\mathrm{H}_{2} \mathrm{O} \rightarrow \mathrm{Al}(\mathrm{OH})_{3}+\mathrm{H}^{+}
\end{aligned}
$$

In practice, soluble $\mathrm{Al}^{3+}$ cations is predominant when $\mathrm{pH}$ is lower than 4 . As the $\mathrm{pH}$ increases, the trivalent aluminum ions go through hydrolysis, and form the monomeric hydroxyl species. With $\mathrm{pH}$ below 4, soluble $\mathrm{Al}^{3+}$ cations can be dominant. As the $\mathrm{pH}$ value increases, $\mathrm{Al}^{3+}$ cations will be subject to hydrolysis and form monomeric hydroxyl species at the beginning like $\mathrm{Al}(\mathrm{OH})^{2+}$, $\mathrm{Al}(\mathrm{OH})_{2}{ }^{+}, \mathrm{Al}_{2}(\mathrm{OH})_{2}{ }^{4+}$ and $\mathrm{Al}(\mathrm{OH})_{4}{ }_{4}$, eventually polymeric hydroxyl species such as $\mathrm{Al}_{6}(\mathrm{OH})_{15^{3+}}$ and $\mathrm{Al}_{7}(\mathrm{OH})_{17^{4+}}$ (Mollah et al. 2004). Above $\mathrm{pH} 9$, soluble $\mathrm{Al}(\mathrm{OH})_{4}^{-}$mainly presents in the solution. The solid $\mathrm{Al}(\mathrm{OH})_{3}$ is most prevalent when $\mathrm{pH}$ is around 7. These formed monomeric and polymeric aluminum hydroxide species finally convert into amorphous $\mathrm{Al}(\mathrm{OH})_{3}(\mathrm{~s})$ according to complicated precipitation kinetics. The higher pollutant removal efficiencies at either acidic or alkaline condition than at neutral is mainly attributed to the formation of aluminum hydroxide flocs in corresponding $\mathrm{pH}$ range. The presence of polymeric aluminum hydroxide over an extended $\mathrm{pH}$ gradient (5.2 to 8.8) would significantly promote the remove of pollutant by the adsorption on coagulant flocs surface. 

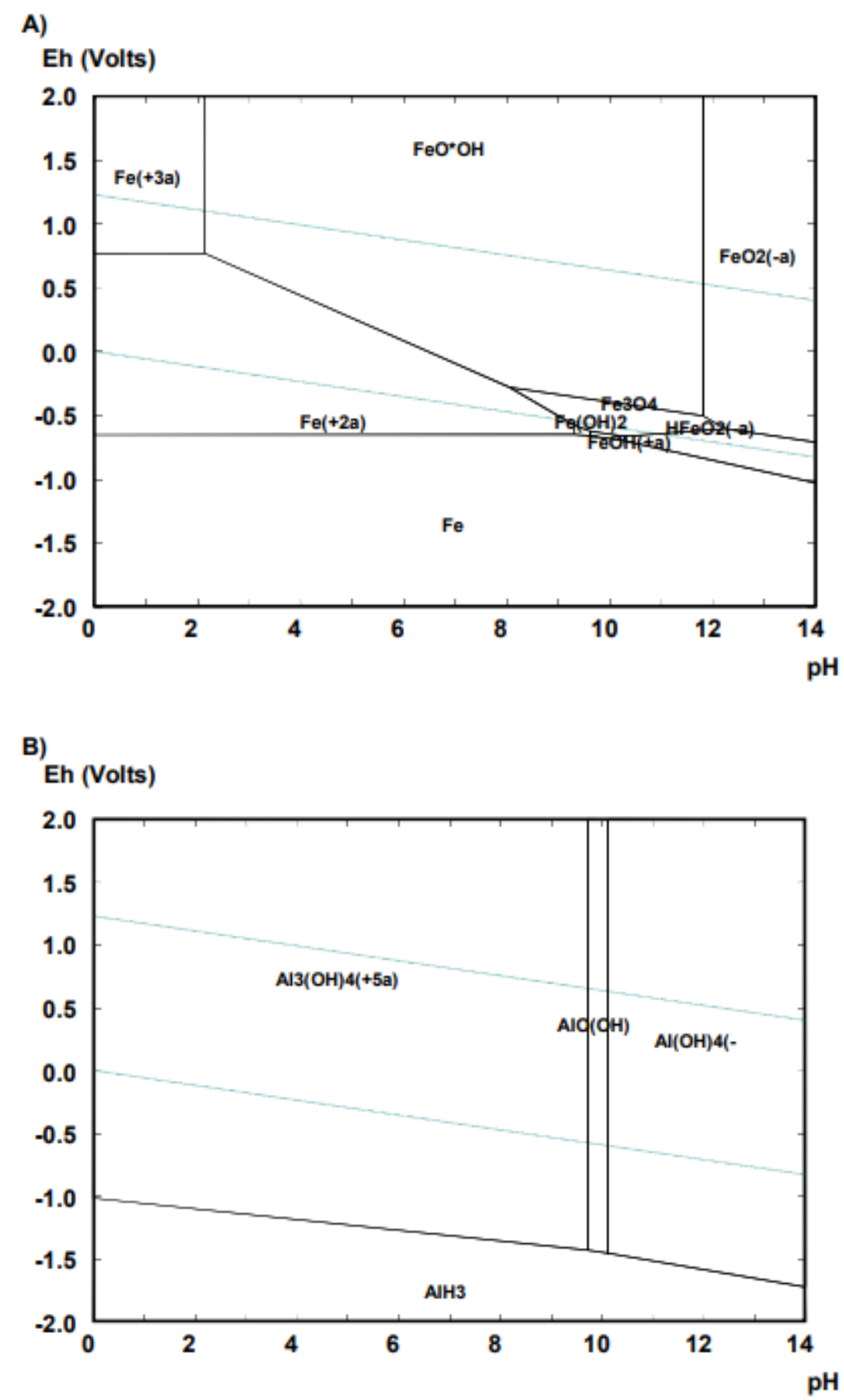

Figure 1.2 E-pH diagrams of: a) Iron and b) Aluminum at $25^{\circ} \mathrm{C}$ (Vepsäläinen 2012).

Aluminum shows amphoteric property in acid/base medium, which provides the no-negligible benefit for using aluminum as electrode material. Beside the electrochemical dissolution of aluminum at anode, the secondary reactions might take place at the electrode due to the purely chemical attack of aluminum in acid or alkaline medium (Eq. 10 and 11). Especially the chemical attack at the cathode electrode, which may become more significant as the increase of localized 
pHs due to continuing $\mathrm{OH}^{-}$generation by water electrolysis. The presence of chloride ions in electrolyte is also proved facilitating the aluminum corrosion (Mouedhen et al. 2008; Lakshmanan et al. 2009; Canizares et al. 2005). It was suggested that both chemical dissolution at cathode (Eq. 11), and electrochemical dissolution at anode (Eq. 10), play an important role in the aluminum generation. It results in a higher amount of aluminum than those expected from the theoretical values calculated by Faraday's law, usually 120-140\% and sometimes up to $200 \%$ (Mouedhen et al. 2008).

The corresponding reaction can be written as follows:

$2 \mathrm{Al}(\mathrm{s})+6 \mathrm{H}^{+} \rightarrow 2 \mathrm{Al}^{3+}+3 \mathrm{H}_{2}(\mathrm{~g})$

$2 \mathrm{Al}(\mathrm{s})+6 \mathrm{H}_{2} \mathrm{O}+2 \mathrm{OH}^{-}(\mathrm{aq}) \rightarrow 2 \mathrm{Al}(\mathrm{OH})_{4}^{-}(\mathrm{aq})+3 \mathrm{H}_{2}(\mathrm{~g})$

\subsubsection{Iron Speciation}

In typical conditions of electrocoagulation process, when iron or steel is used as anode, most results demonstrated that $\mathrm{Fe}^{2+}$, rather than $\mathrm{Fe}^{3+}$, is dissolved from the oxidation of anode according to following reaction (Eq. 12).

$\mathrm{Fe}(\mathrm{s}) \rightarrow \mathrm{Fe}^{2+}+2 \mathrm{e}^{-} \quad$ (Eq. 12)

However, both divalent $\mathrm{Fe}^{2+}$ and trivalent $\mathrm{Fe}^{3+}$ forms can be produced during the electrocoagulation process. It depends on the chemical environment of the system, such as the presence of oxidant and the nature of electrolyte. Compared to the aluminum anode, which only can be dissolved to trivalent $\mathrm{Al}^{3+}$ forms, more complicated reactions take place at iron electrode than aluminum electrode. $\mathrm{Fe}^{3+}$ might be produced under the presence of sufficient concentration of oxygen in the system. On the other hand, acidic pHs increases the corrosion rate of iron electrode, but the dissolution rate of $\mathrm{Fe}^{3+}$ is not significant. As a consequence of the negligible dissolution of iron from chemical corrosion, the total amount of iron generation is around 100\% or below (Sasson et al. 2009; Jiménez et al. 2012; Chen 2004).

Hydroxide ions are generated at the cathode from the water electrolysis (Eq. 13), which cause an increase of electrolyte $\mathrm{pH}$. The generated ferrous ions hydrolyze in water might form various 
monomeric or polymeric hydroxyl species, depending on the ferrous ion concentration and the $\mathrm{pH}$ of aqueous medium, such as $\mathrm{Fe}^{3+}, \mathrm{Fe}(\mathrm{OH})^{2+}, \mathrm{Fe}(\mathrm{OH})_{2}{ }^{+}, \mathrm{Fe}(\mathrm{OH})_{4}{ }^{-}, \mathrm{Fe}\left(\mathrm{H}_{2} \mathrm{O}\right)_{5}(\mathrm{OH})^{2+}$, and $\mathrm{Fe}\left(\mathrm{H}_{2} \mathrm{O}\right)_{4}(\mathrm{OH})_{2}{ }^{+}$. The insoluble $\mathrm{Fe}(\mathrm{OH})_{2}$ mainly forms at $\mathrm{pH}$ larger than 5.5 (Eq. 14) and precipitates as $\mathrm{Fe}(\mathrm{OH})_{3}$ with the presence of hydrogen at higher $\mathrm{pH}$ values according to the following reactions (Eq. 15) (Martínez-Huitle and Brillas 2009).

$$
\begin{aligned}
& \mathrm{Fe}^{2+}+2 \mathrm{H}_{2} \mathrm{O}+\mathrm{O}_{2}(\mathrm{~g}) \rightarrow \mathrm{Fe}^{3+}+4 \mathrm{OH}^{-} \\
& \mathrm{Fe}^{2+}+2 \mathrm{OH}^{-} \rightarrow \mathrm{Fe}(\mathrm{OH})_{2} \\
& 4 \mathrm{Fe}^{2+}+10 \mathrm{H}_{2} \mathrm{O}+\mathrm{O}_{2}(\mathrm{~g}) \rightarrow
\end{aligned}
$$

It is important to notice that there are two theoretical differences in the chemical properties of iron and aluminum, which might influence the electrocoagulation performance for removal of pollutant from wastewater. The first one is the better buffer effect of aluminum than iron. The solution $\mathrm{pH}$ usually keeps in a relative effective range with aluminum electrode. While for iron electrode, solution $\mathrm{pH}$ can increase up to 10 even when the initial $\mathrm{pH}$ is acidic, and it may require $\mathrm{pH}$ neutralization at downstream (Chafi et al. 2011; Hakizimana et al. 2017). As a result, aluminum electrode can be used in a wide range of $\mathrm{pH}$ for aqueous medium, and it works with a high dissolution efficiency of aluminum during electrocoagulation process. The other difference is the poor coagulant capability of $\mathrm{Fe}^{2+}$ compared with $\mathrm{Fe}^{3+}$ and $\mathrm{Al}^{3+}$ due to higher solubility of hydroxides. It is known that the general $\mathrm{K}_{\mathrm{sp}}$ values for $\mathrm{Fe}^{2+}, \mathrm{Fe}^{3+}$ and $\mathrm{Al}^{3+}$ are $4.9 \times 10^{-17}, 2.6 \times 10^{-}$ ${ }^{39}$, and $1.9 \times 10^{-33}$, respectively. This characteristic of $\mathrm{Fe}^{2+}$ leads to the poor removal efficiency of pollutant by electrocoagulation with iron electrodes compared to aluminum in several research results. Therefore, improving the $\mathrm{Fe}^{3+}$ production is a common approach to optimize electrocoagulation efficiency.

Beside the high coagulant capability of $\mathrm{Fe}^{3+}$, some studies have reported that the oxidation reaction from $\mathrm{Fe}^{2+}$ to $\mathrm{Fe}^{3+}$ might facilitate the reduction of $\mathrm{Cr}$ (VI) to $\mathrm{Cr}$ (III) (Heidmann and Calmano 2008a). Traditionally, $\mathrm{Cr}(\mathrm{VI})$ is reduced to $\mathrm{Cr}(\mathrm{III})$ prior to precipitation as $\mathrm{Cr}(\mathrm{OH})_{3}$. During the electrocoagulation process, the reduction of $\mathrm{Cr}(\mathrm{VI})$ can occur through two ways, depending on the applied current. The high current accelerates the transportation of electrons between anode and cathode electrodes. The reduction of $\mathrm{Cr}(\mathrm{VI})$ could occur directly at the cathode surface (Eq. 16). 
At low current, $\mathrm{Fe}^{2+}$ is believed to serve as an agent for reducing $\mathrm{Cr}$ (VI) to $\mathrm{Cr}$ (III) followed by precipitation as $\mathrm{Cr}(\mathrm{OH})_{3}$. (Eq. 18). At this point, optimal electrode material should be selected according to the certain pollutants and the operational parameters during electrocoagulation process.

$$
\begin{aligned}
& \mathrm{Cr}_{2} \mathrm{O}_{7}^{2-}+6 \mathrm{e}^{-}+7 \mathrm{H}_{2} \mathrm{O} \rightarrow 2 \mathrm{Cr}^{3+}+14 \mathrm{OH}^{-} \\
& \mathrm{Cr}_{2} \mathrm{O}_{7}^{2-}+6 \mathrm{Fe}^{2+}+7 \mathrm{H}_{2} \mathrm{O} \rightarrow 2 \mathrm{Cr}^{3+}+6 \mathrm{Fe}^{3+}+14 \mathrm{OH}^{-} \\
& \mathrm{Cr}(\mathrm{aq})^{3+}+3 \mathrm{OH}^{-} \rightarrow \mathrm{Cr}(\mathrm{OH})_{3}(\mathrm{~s})
\end{aligned}
$$

\subsubsection{Key Parameters for EC Process}

There are several parameters which can effect EC performance for removing the pollutants from wastewater, including the operating conditions such as electrode materials, electrode arrangement, current density, treatment time and temperature. Furthermore, the waster matrix features such as $\mathrm{pH}$, conductivity, contaminant composition and pollutant concentrations. The key parameters are discussed in this section.

\subsubsection{Current Density}

Current density is considered as a very important parameter of EC because it determines the coagulant dosage by controlling the amount of metal ions and hydroxide ions produced from the electrode. Generally, the amount of released metal ions can be calculated by Faraday's law (Eq. 5), which shows the metal dissolution is proportional to the applied current density. With the increase of current density, the anode electro-dissolution and water electrolysis rate increases. It leads to the formation of more coagulant flocs and finally results in the increase of pollutant removal efficiency. However, it should be noted that, in some case, the amount of metal ions generated does not fit the theoretical value obtained by Faraday's law. This fact might be attributed to the presence of chemical dissolution of metal ions and energy loss for heating water during EC process. These issues lead to over $100 \%$ current efficiency or waste of electrical energy (Picard et al. 2000; Canizares et al. 2005; Heidmann and Calmano 2008b). Therefore, it is worth noting that 
the high current density is not always favorable for effective removal of pollutants from wastewater by EC process.

\subsection{6 pH}

$\mathrm{pH}$ is the another key parameter significantly affecting the EC performance, which is related to the conductivity of solution, zeta potential and electrode dissolution. Importantly, the solubility and speciation of coagulants are strongly dependent with $\mathrm{pH}$. As discussed in previous aluminum and iron electrode speciation, the effective aluminum and iron hydroxides coagulants generated at different $\mathrm{pH}$ ranges. It explains how $\mathrm{pH}$ contributes to the electrocoagulation mechanism. Nevertheless, due to the changing $\mathrm{pH}$ during EC process, it is difficult to relate the $\mathrm{pH}$ of the treated water with the efficiency of EC. Beside the continue generation of hydroxide ions and the corresponding consumption for formation of hydroxides coagulants, water oxidation to produce hydrogen ions at anode as an important side reaction also leads to the change of solution $\mathrm{pH}$. Additionally, the different initial $\mathrm{pH}$ affect the occurred reactions during EC process resulting in the different $\mathrm{pH}$ ranges. For acidic media, the increase of $\mathrm{pH}$ is due to the generation of hydroxide ions and hydrogen escape. For alkaline media, the formation of hydroxides precipitation is favorable with the relative high concentration of hydroxide ions, simultaneously releasing hydrogen ions at the anode. The process results in the decrease of $\mathrm{pH}$ after EC process. Therefore, most of the studies about effect of solution $\mathrm{pH}$ on EC performance refer to the initial $\mathrm{pH}$ of solution (Hakizimana et al. 2017; Moussa et al. 2017).

\subsection{Comparison of Electrocoagulation and Chemical Coagulation}

Coagulation process has been reported as the most common and effective method to remove several types of pollutants from wastewater. The main idea of coagulation is to precipitate pollutants as an insoluble form followed by separation processes. The chemical coagulation of pollutants is usually achieved by addition of chemical coagulants. For example, sodium hydroxide can be added to adjust the $\mathrm{pH}$ of wastewater then precipitate heavy metals ions as insoluble hydroxides. Metal salt like iron or aluminum also can be used as coagulants to remove pollutants as colloidal matter or to improve settlement characteristics of pollutants (Agridiotis et al. 2007). 
Despite chemical coagulation can be a fine way to effectively remove pollutants, the method is not considered low cost. Moreover, adding chemicals into wastewater may produce side products which are considered secondary pollution. An alternative for the chemical coagulation process is electrocoagulation, which shares the same pathway with chemical coagulation to remove pollutants by the presence of coagulants. But instead of chemicals addition in chemical coagulation, electrocoagulation in situ generates coagulants by the electro-dissolution of sacrificial anode, usually made of aluminum or iron.

Some researchers are aiming to provide a comparison between chemical coagulation and electrocoagulation based on the related parameters such as removal efficiency, coagulants generated and change of $\mathrm{pH}$, even the removal mechanism (Canizares et al. 2009; Vepsäläinen 2012; Zhu et al. 2005; Holt et al. 2002; Emamjomeh and Sivakumar 2009). Zhu et al (2005) compared EC and chemical coagulation pretreatment for enhanced virus removal using microfiltration membranes. The result suggested that EC outperformed chemical coagulation pretreatment for virus removal, also EC is more effective than chemical coagulation for nature organic matter removal. Holt et al (2002) quantitatively compared chemical dosing and electrocoagulation. The authors proposed that the different performance between chemical dosing and electrocoagulation mainly attributed to the different mechanism of coagulant delivery. Emamjomeh and Sivakumar (2009) focused on the removal of turbidity. The study compared chemical coagulation and electrocoagulation from multiple levels, including removal efficiency, size of coagulant flocs formed, and the amount of sludge generated. The results showed that EC process was more efficient to remove turbidity than chemical coagulation process and led to larger floc size, while generated much less total volume of sludge.

\subsection{Advantages and disadvantages of electrocoagulation}

Several advantages of electrocoagulation process have been reported (Mollah et al. 2001; Hakizimana et al. 2017).

i. There is no chemicals additions, so it causes to an extremely low secondary pollution.

ii. EC can be easily operated with the simple required equipment and automatic procedure. 
iii. Electrocoagulation process is preferred in the case of organic pollutants than chemical coagulation due to higher effectiveness. EC also requires less aluminum dosage when aluminum is anode.

iv. Low sludge is produced by EC compared with chemical coagulation.

v. EC is capable of coagulating the small colloidal particles due to the effective destabilization resulted from the applied electric field.

At the same time, there are some main drawback for EC process:

i. The sacrificial anodes is consumed during EC process, and it needs to be replaced periodically.

ii. Cathode passivation inhibits the flow of electronic current. Change of polarity or using different type of power supply may reduce this limitation (Vasudevan et al. 2011).

iii. In the case of effluent with low dissolved solids, EC application is limited due to its requirement for a minimum conductivity of treated solution.

iv. The high operation cost results from electricity requirement in EC process.

It should be noted that the high operational cost, especially the power supply, is the main issue which limits the application of electrocoagulation when electricity is not abundant around. But from 90s, the further improvement of technology and the rediscovery of lot advantages of electrocoagulation brought people's attention back to electrocoagulation. The electrocoagulation can even be easily used in rural areas since it only require a low current. Nowadays, the power can be supplied by green technologies such as solar or wind, effectively decreasing the operation cost. Moreover, electrocoagulation has also been combined with other techniques, such as filtration, flotation, sedimentation, chemical coagulants and biofiltration, in order to further improve the electrocoagulation performance (Vepsäläinen 2012). 


\subsection{Electrocoagulation for Heavy Metal Removal}

\subsubsection{Heavy Metal Contaminations}

Industrial wastewaters has become a great issue as the rapid development of traditional industries, such as electroplating, mining operations, tanneries, batteries and paper mill and factories. Numerous toxic heavy metals contained in theses industrial wastewaters are directly discharged into the environment without treatment. These heavy metals includes but not limits to chromium, nickel, copper, zinc, mercury and lead. Heavy metals cannot be biodegraded. On the contrary, it accumulates in living organisms. Some are known to be toxic or carcinogenic. For example, zinc is an essential trace element to human body. A proper amount of zinc is pivotal for physiological functions of living tissue and metabolism. However, zinc over dosage can cause stomach cramps, skin irritations, vomiting, nausea and anemia (Oyaro et al. 2007). Nickel over dosage can lead to serious lung and kidney problems aside from gastrointestinal distress, pulmonary fibrosis and skin dermatitis (Borba et al. 2006). Excessive copper brings about vomiting, cramps, convulsion and even death. (Paulino et al. 2006). Heavy metals are environmental priority concerns currently and demand high attention to cope with related contaminations.

\subsubsection{Current Technology for Heavy Metals Removal}

Current technology for heavy metal removal are chemical precipitation, ion-exchange (Rudnicki et al. 2014), adsorption ( $\mathrm{Li}$ et al. 2017), membrane filtration, electrochemical treatment techniques (Mo et al. 2015), etc. It is also reported that the combination of multiple methods displays a more effective heavy metal treatment. The most common way is to combine electrocoagulation and electroflotation process. Following such process, the pollutant particles are destabilized and aggregated with coagulants through electrocoagulation. Simultaneously, the produced flocs are floated to the solution surface by electrocoagulation (Chen et al. 2000). Beside the electrocoagulation, a combined electrocoagulation and other filtration methods which are used in post-treatment, such as filter paper, micro- and ultra-filtration, to removal heavy metal from wastewater (Gao et al. 2005; Sun et al. 2009). Additionally, the electrocoagulation can be 
combined with the coagulation to remove multiple pollutants include organic particles and heavy metal ions from wastewater (Holt et al. 2005).

\subsubsection{Research Goal}

In this study, the EC process was used to remove metal ions such as $\mathrm{Zn}, \mathrm{Cu}, \mathrm{Fe}, \mathrm{Mn}, \mathrm{Mg}, \mathrm{Ca}, \mathrm{Ba}$ and $\mathrm{Sr}$ from model wastewater, among which zinc will be focused. This work was completed in accordance with the following three specific objectives:

Objective 1: Estimate the feasibility of EC process with aluminum electrodes to remove metals ions from variable wastewater, such as model water with either a trace or high concentration of zinc ions.

Objective 2: Understand the effect of main parameters on EC performance in terms of removal efficiency and energy consumption. Major parameters such as solution conductivity, initial $\mathrm{pH}$, electrode distance, current density and initial zinc concentration were systematically investigated.

Objective 3: Study kinetics of the EC process and propose possible removal pathway for metal ions by $\mathrm{EC}$. 


\section{Experimental Sections and Characterizations}

\subsection{Model Water Preparation}

Synthesized wastewater with different metal concentrations (from 50 to $2000 \mathrm{mg} / \mathrm{L}$ ) was prepared by dissolving the corresponding amount of $\mathrm{ZnSO}_{4} \cdot 7 \mathrm{H}_{2} \mathrm{O}$ (Alfa Aesar, ACS 99.0-103.0\%), $\mathrm{CuSO}_{4} \cdot 5 \mathrm{H}_{2} \mathrm{O}$ (Alfa Aesar, $99 \%$ ), $\mathrm{MnSO}_{4}$ (broworld, $98 \%$ ), $\mathrm{BaCl}_{2} \cdot 2 \mathrm{H}_{2} \mathrm{O}$ (Alfa Aesar, $99 \%$ ), $\mathrm{FeCl}_{3} \cdot 6 \mathrm{H}_{2} \mathrm{O}$ (Acros Organics, $99 \%$ ) and $\mathrm{SrCl}_{2} \cdot 6 \mathrm{H}_{2} \mathrm{O}$ (Alfa Aesar, $99 \%$ ) in deionized (DI) water. Conductivity of the synthesized wastewater was adjusted by adding $\mathrm{NaCl}$ (Fisher Chemical, ACS $99.6 \%$ ) with a conductivity increase from 0.15 to $14.11 \mathrm{mS} / \mathrm{cm}$. Solution conductivity was measured using an Ohaus conductivity meter (Ohaus, USA). Initial solution pH was adjusted using $\mathrm{HCl}$ and $\mathrm{NaOH}$ solutions and measured using a pH meter (Pen Meter, Extech). Deionized water was used in all the experiments.

\subsection{Device Setup}

Figure 2.1 shows a schematic diagram of the EC setup at laboratory scale. A $400 \mathrm{~mL}$ beaker filled with $300 \mathrm{~mL}$ model water was employed as the EC reactor for all attempts in this study. Two aluminum plates with dimensions of $100 \mathrm{~mm} \times 40 \mathrm{~mm} \times 3 \mathrm{~mm}$ (length $\times$ width $\times$ depth) were used as electrodes. The effective surface area of anodic electrodes immersed in wastewater was $24 \mathrm{~cm}^{2}$. A pre-defined current from 0.05 to $0.30 \mathrm{~A}$ was applied using a DC power supply. During the EC process, the solution was continuously stirred using Teflon coated stir bar at a rotational speed of $200 \mathrm{rpm}$ at ambient temperature.

\subsection{Sampling}

Water samples with a volume of 2-5 mL were taken periodically from the reactor at pre-determined time intervals, then filtrated using filter papers (Whatman, Grade 4, 20-25 $\mu \mathrm{m}$ ). After EC treatment, the precipitation was separated and collected by filtration of bulk solution, then dried at $75{ }^{\circ} \mathrm{C}$ for $24 \mathrm{~h}$ in an oven. The obtained precipitation was dissolved using $70 \% \mathrm{HNO}_{3}$ and followed with a 
10 times dilution. All these solution samples were sent to test zinc $\left(\mathrm{Zn}^{2+}\right)$ and aluminum $\left(\mathrm{Al}^{3+}\right)$ concentrations. Deposition formed on the cathode surface under high zinc concentrations was collected, then sampled after drying.

Zinc removal efficiency (\%) was calculated using Eq. 19:

Removal Efficiency $(\%)=\frac{C_{0}-C_{t}}{C_{0}} \times 100$

where $C_{0}$ and $C_{t}$ are the initial and final zinc ions concentrations, respectively.

The electrical energy consumption per volume of the treated wastewater is determined using Eq. 20:

$E=\frac{U I t}{V}$

where $E$ is the energy consumption $\left(\mathrm{kWh} / \mathrm{m}^{3}\right), U$ is the operated voltage $(\mathrm{V}), I$ is the DC current (A), $t$ is the EC time (h), and $\mathrm{V}$ is the volume of the treated wastewater (L).

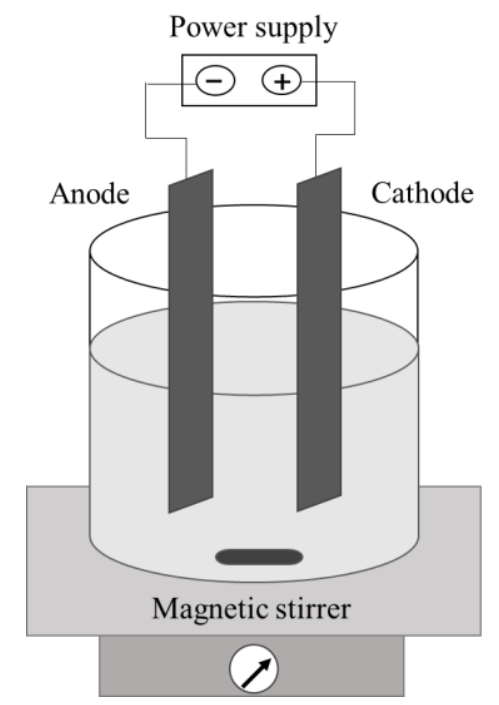

Figure 2.1 Schematic diagram of experimental setup.

\subsection{Characterizations}

Upon EC treatment, the model water was filtered to separate precipitation. Zinc $\left(\mathrm{Zn}^{2+}\right)$ and aluminum $\left(\mathrm{Al}^{3+}\right)$ concentrations were measured by inductively coupled plasma-optical emission 
spectroscopy (ICP-OES) (Palo Alto, USA). The morphology and elemental analysis of solid byproducts of EC were characterized using scanning electron microscope (SEM) partnered with energy dispersive X-ray spectroscopy (EDX) (Hitachi, S-4700F w/ EDAX system, Japan). The precipitation samples were analyzed using an X-ray diffractometer (XRD) (PANalytical X'Pert Pro, Almelo, Netherlands) with a $\mathrm{Cu} \mathrm{K} \alpha \mathrm{X}$-ray source. The X-ray photoelectron spectroscopy XPS measurements were carried out using a Physical Electronics, PHI 5000 Versa Probe (XPS/UPS) spectrometer (Chanhassen, MN) with a monochromatic $\mathrm{Al} \mathrm{K \alpha}$ source operated at $300 \mathrm{~W}$ and a base pressure of $1 * 10^{-7}$ Torr. 


\section{Effect of Reactor and Water Matrix Parameters on Metal Ions Removal}

EC is a complicated process which includes many physical changes and chemical reactions. It is affected by many parameters, such as pollutant concentration, initial $\mathrm{pH}$, current density and wastewater conductivity. In the present study, the effect of these parameters on $\mathrm{Zn}^{2+}$ removal from model wastewater by aluminum EC process was systematically investigated. Additionally, the EC energy consumption was also considered in evaluating and enhancing removal performance.

\subsection{Reactor Parameters}

\subsubsection{Effect of Current Density on EC Performance}

Current density is believed as the most important factors affecting the EC performance, as it determines coagulant production by controlling the amount of $\mathrm{Al}^{3+}$ released at anode and $\mathrm{OH}^{-}$ generated at cathode. In order to further investigate the role of formed aluminum hydroxide in removing $\mathrm{Zn}^{2+}$, it is necessary to trace the evolution of solution $\mathrm{pH}$ and $\mathrm{Al}^{3+}$ concentration during EC process.

In present study, the experiments were conducted using current densities of 2.1, 4.2, 8.3 and 12.5 $\mathrm{mA} / \mathrm{cm}^{2}$. Initial $\mathrm{Zn}^{2+}$ concentration was fixed to $50 \mathrm{mg} / \mathrm{L}$. Figure 3.1 a shows the evolution of bulk solution $\mathrm{pH}$ during $\mathrm{EC}$ process. The solution $\mathrm{pH}$ slightly decreased at the beginning of EC treatment then reached a stable period, but quickly increased with further EC time. It was noted that the duration time of stable period was much shorter with higher current density. The $\mathrm{pH}$ evolutions could be related to the generation of hydroxide ions by electrolysis and consumption due to formation of aluminum hydroxide coagulant during the EC process. When most of $\mathrm{Zn}^{2+}$ were removed, more hydroxide ions were presented in bulk solution, leading to increasing solution pH (Heidmann et al. 2010).

Figure $3.1 \mathrm{~b}$ shows the variations of residual $\mathrm{Al}^{3+}$ concentration during EC process under different current densities. $\mathrm{Al}^{3+}$ concentration increased as the anode dissolution in the beginning then 
decreased to a minimum value around $0.06,0.06,0.01$ and $0.03 \mathrm{mg} / \mathrm{L}$ at $10,15,25$ and $30 \mathrm{~min}$ with current density of $12.5,8.3,4.2$ and $2.1 \mathrm{~mA} / \mathrm{cm}^{2}$, respectively. The reduction of residual $\mathrm{Al}^{3+}$ concentrations can be ascribed to the precipitation of $\mathrm{Al}(\mathrm{OH})_{3}$ during the EC process. The excessive EC treatment resulted in a significant increase of $\mathrm{Al}^{3+}$ concentration, which might present as $\left[\mathrm{Al}(\mathrm{OH})_{4}\right]^{-}$(Jiménez et al. 2012). Moreover, it is worthwhile to point out that, the residual $\mathrm{Al}^{3+}$ concentration (when most of $\mathrm{Zn}^{2+}$ were removed) is much lower than the value recommended by WHO (200 ppb) (Hernández et al. 2010; Mouedhen et al. 2008). This result indicated the environmental compatibility of EC method for heavy metal treatment without secondary pollution. This is also one of the important advantages of EC method compared with chemical precipitation (Bazrafshan et al. 2012).

Figure 3.1c shows the variation of $\mathrm{Zn}^{2+}$ removal efficiency with time at different current densities. Removal efficiency increased as increasing with current density while, simultaneously decreasing required EC time. For 95\% $\mathrm{Zn}^{2+}$ removal, it required 30, 25, 20 and $15 \mathrm{~min}$ at the 2.1, 4.2, 8.3 and $12.5 \mathrm{~mA} / \mathrm{cm}^{2}$, respectively. This result was in good agreement with Faraday's law. Increasing the current density leads to a higher $\mathrm{Al}^{3+}$ and $\mathrm{OH}^{-}$dosage with time, thereby increasing $\mathrm{Al}(\mathrm{OH})_{3}$ coagulant formation, and the EC process is accelerated. Excessive time resultsed in a reduction of zinc removal efficiency. It might be explained by the formation of $\left[\mathrm{Al}(\mathrm{OH})_{4}\right]^{-}$. When most of the $\mathrm{Zn}^{2+}$ was removed, the excessive EC time leads to more hydroxide ions present in the solution, the soluble species $\left[\mathrm{Al}(\mathrm{OH})_{4}\right]^{-}$becomes dominant product (As shown in Figure 3.2 ), which is not favorable for $\mathrm{Zn}^{2+}$ removal.

According to the evolutions of solution $\mathrm{pH}, \mathrm{Al}^{3+}$ concentration and removal efficiency, it could be clearly noted that, after EC durations of 30, 25, 20 and 15 min at current densities of 2.1, 4.2, 8.3 and $12.5 \mathrm{~mA} / \mathrm{cm}^{2}$, respectively, the solution $\mathrm{pH}$ started to rise, simultaneously, the $\mathrm{Al}^{3+}$ concentrations decreased to minimum value. Moreover, these duration time matched the required time to achieve $95 \% \mathrm{Zn}^{2+}$ removal. It strongly confirmed the $\mathrm{Zn}^{2+}$ removal could be ascribed to the generated aluminum hydroxide coagulant. 

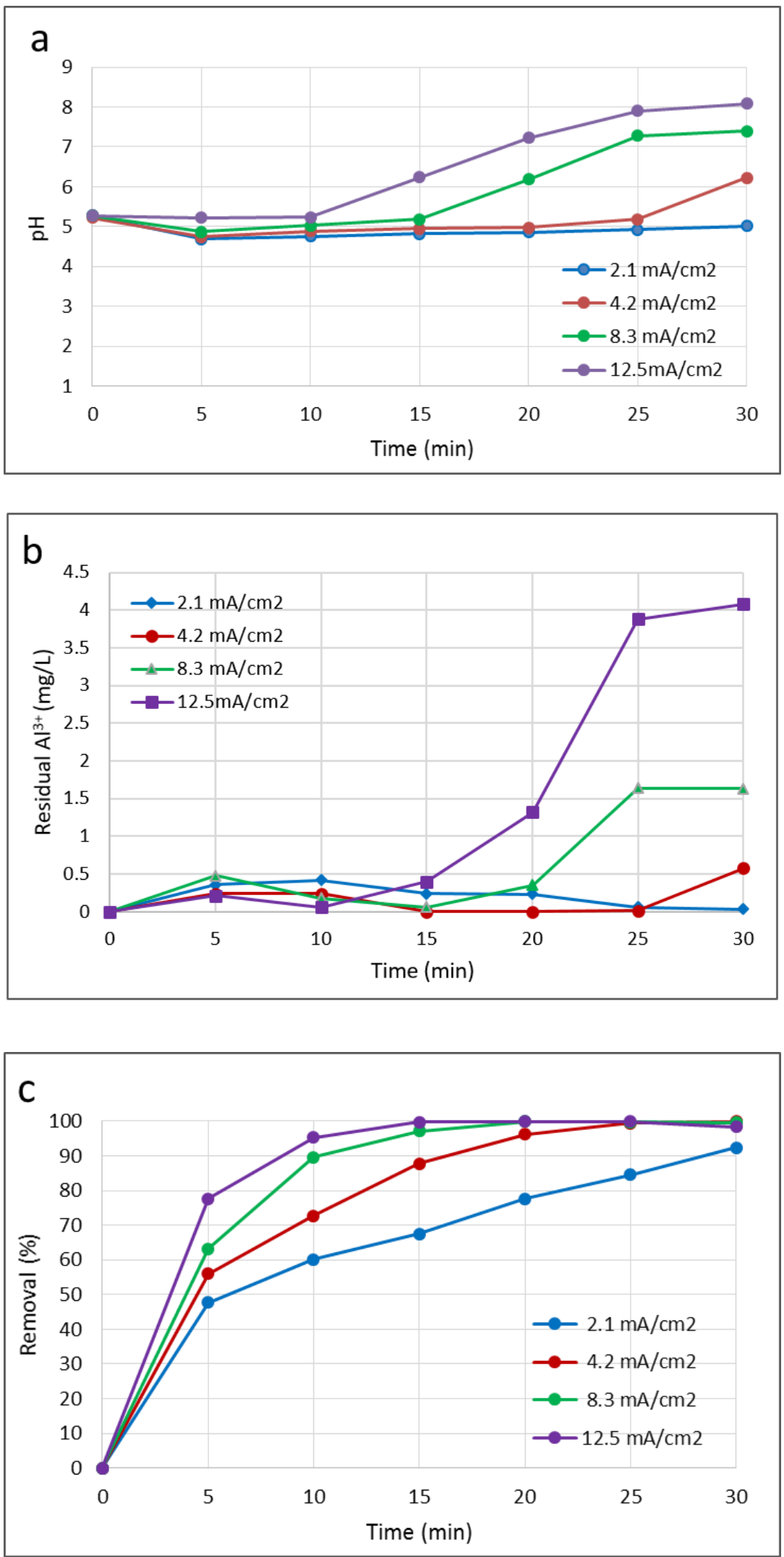


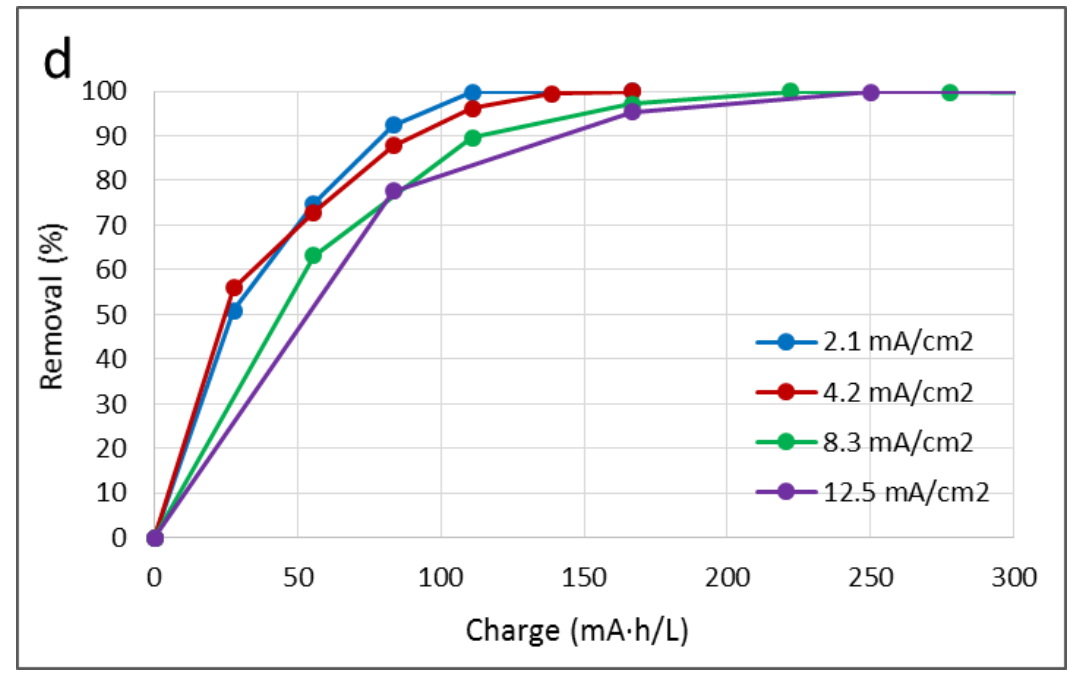

Figure 3.1 Evolution of solution $\mathrm{pH}(\mathrm{a})$, residual $\mathrm{Al}^{3+}$ concentration (b), $\mathrm{Zn}^{2+}$ removal efficiency with EC time at different current densities (c), influence of current density on $\mathrm{Zn}^{2+}$ removal against charge loading(d). $\mathrm{C}_{0}=50 \mathrm{mg} / \mathrm{L}, \sigma=9.72 \mathrm{mS} / \mathrm{cm}, \mathrm{d}=1.0 \mathrm{~cm}$.

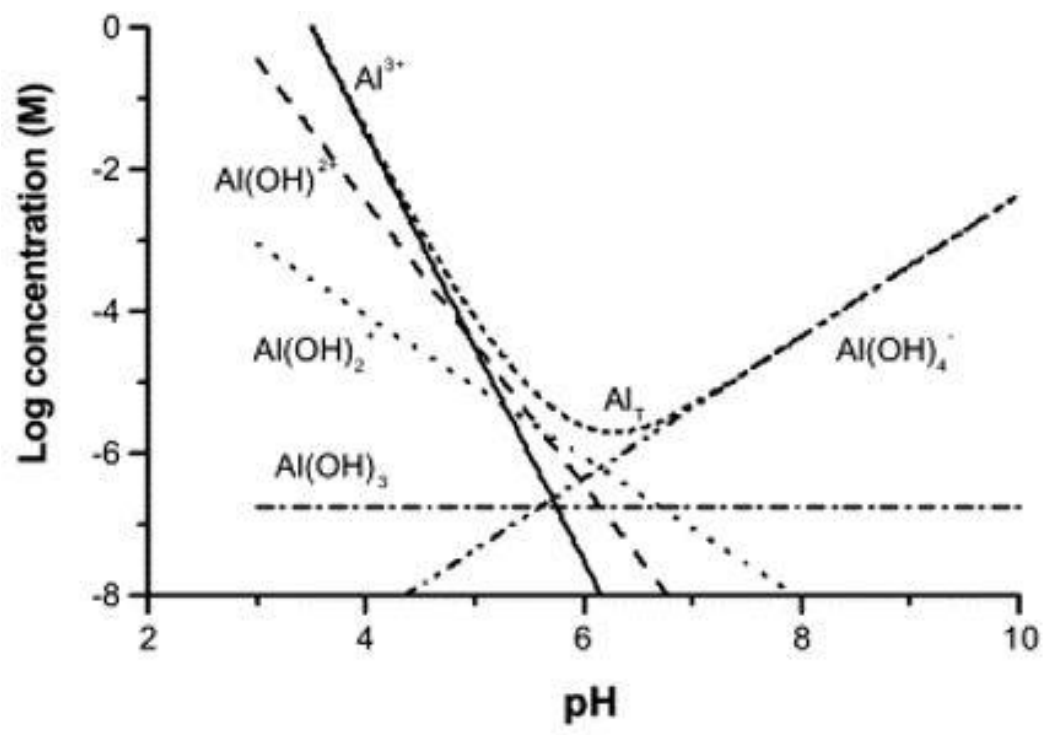

Figure 3.2 Concentrations of monomeric hydrolysis products of $\mathrm{Al}(\mathrm{III})$ in equilibrium with the amorphous hydroxides, at zero ionic strength and $25^{\circ} \mathrm{C}$ (Duan et al. 2003).

As proved above, the $\mathrm{Zn}^{2+}$ removal process was accelerated by increasing applied current density. It seems $\mathrm{Zn}^{2+}$ removal performance should not be evaluated according to current density without 
EC time, so the charge loading was considered as an appropriate parameter in this case. Figure 3.1d shows the relationship between removal efficiency and charge loading at different current densities. Generally observing, the $\mathrm{Zn}^{2+}$ removal efficiency increased in dependence on the applied charge. However, it did not result in significant efficiency improvement when current density was increased beyond a certain level. Compared with current density of $8.3 \mathrm{~mA} / \mathrm{cm}^{2}$, there is a negligible change in removal efficiency when current density was increased to $12.5 \mathrm{~mA} / \mathrm{cm}^{2}$. At high current densities, it is likely not all of aluminum was converted into abundant coagulant dosage at a short time. High current density led to a large amount of $\mathrm{Al}^{3+}$ and $\mathrm{OH}^{-}$were produced in a short time, and these ions were not completely converted into effective coagulants (aluminum hydroxide flocs), resulting in a low current efficiency. There might be a high chance of energy loss in heating water or oxygen formation at the anode under higher current density (Moussa et al. 2012; Heidmann et al. 2008). Some reports also ascribed this behavior to higher kinetic and over potential (Mouedhen et al. 2008). Moreover, higher operating voltage was required at higher current density induced, which led to more energy consumption. For current densities of 2.1, 4.2, 8.3 and 12.5 $\mathrm{mA} / \mathrm{cm}^{2}$, the operating voltages were $1.0,1.2,1.5$ and $1.8 \mathrm{~V}$, respectively. Never the less, the high current densities caused dramatic bubble generation (Figure 3.3), which made the separation of precipitation more efficient. This process was also known as electroflotation (EF). Combination of EC and EF has been reported as a promising approach for removal of heavy metal ions from wastewater (Gao et al. 2005; Chen et al. 2000; Sun et al. 2009).
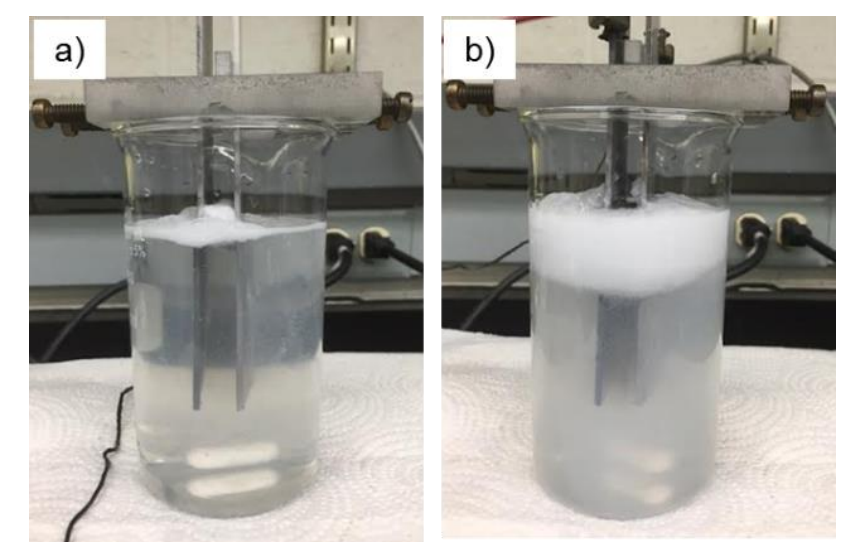

Figure 3.3 Influence of current density on bubble generation during EC: (a) $2.1 \mathrm{~mA} / \mathrm{cm}^{2}$; (b) 12.5 $\mathrm{mA} / \mathrm{cm}^{2}$. 


\subsubsection{Effect of Electrode Spacing on EC Performance}

Industrial wastewater has a substantial solution conductivity, which can meet the basic conductive requirement of EC process. Hence, energy consumption with respect to IR-drop could be cut by adjusting electrode spacing (Mollah et al. 2004). Figure 3.4 shows the removal efficiency and cell voltage with different electrode spacing. Only a slight variation of removal efficiency was observed when the electrode spacing varied from 1.0 to $4.0 \mathrm{~cm}$ (Figure 3.4 bar graph). It indicated that the effect of electrode spacing on $\mathrm{Zn}^{2+}$ removal efficiency was not significant in this case. The result was in disagreement with other studies which showed notable improvement on removal efficiency as decreasing electrode spacing (Murthy et al. 2011). The slight variation of $\mathrm{Zn}^{2+}$ removal efficiency in this case was due to the sufficient solution conductivity $(9.72 \mathrm{mS} / \mathrm{cm})$. In addition to removal efficiency, the pseudo-stationary voltage was observed to rapidly decrease with electrode spacing (Figure 3.4 line graph), due to the lower IR-drop across the solution. With a constant applied current, power usage decreased with shorter spacing (Hernández et al. 2012). The following attempts were completed with an electrodes spacing of $1.0 \mathrm{~cm}$.

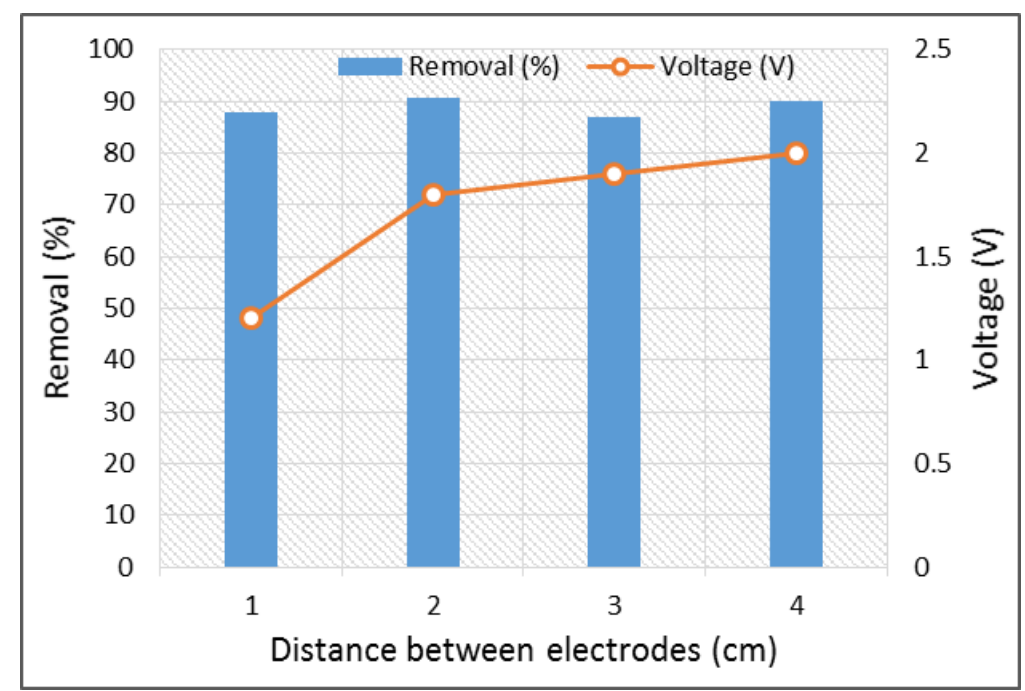

Figure 3.4 Effect of electrode spacing on $\mathrm{Zn}^{2+}$ removal. $\mathrm{C}_{0}=50 \mathrm{mg} / \mathrm{L}, \mathrm{CD}=4.2 \mathrm{~mA} / \mathrm{cm}^{2}, \sigma=$ $9.72 \mathrm{mS} / \mathrm{cm}, \mathrm{t}=15 \mathrm{~min}, \mathrm{pH}_{\text {initial }}=5.25 \pm 0.03$. 


\subsubsection{Effect of Electrodes Arrangement on EC Performance}

In order to clearly understand the EC process, the basic two-electrode EC cell is generally adopted at lab scale. While for industrial scale, the two-electrode EC cell with limited surface area is not suitable for removing heavy metals from wastewater. A workable dissolution rate of the sacrificial metal electrode is required. Common ways to solve this problem is to employ electrodes with large surface area or use multiple electrodes. For EC cell with multiple electrodes, there are several electrode arrangement which may be used. Generally, electrodes can be monopolar or bipolar. Here, the bipolar EC system with four aluminum electrodes are used to study the removal of $\mathrm{Zn}^{2+}$ compared with the two-electrode EC system, as shown in Figure 3.5.

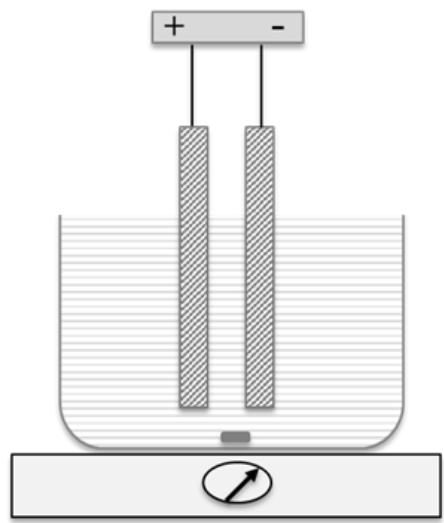

(a)

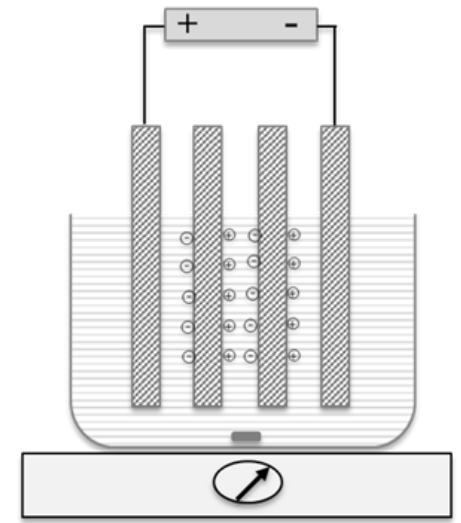

(b)

Figure 3.5 Sketch of the EC systems with: (a) two aluminum electrodes and (b) dipolar electrodes. Electrode spacing is $1.0 \mathrm{~cm}$ in both systems.

In this bipolar system (Figure 3.5b), only the outermost electrodes are connected to a DC power source with no interconnections between the inner electrodes. The interconnected electrodes can be negatively polarized when current passes. Figure 3.6 shows the variation of $\mathrm{Zn}^{2+}$ removal efficiency with different electrodes arrangement. It is clear that the bipolar EC system results in a high $\mathrm{Zn}^{2+}$ removal efficiency. Over $99 \% \mathrm{Zn}^{2+}$ removal was achieved after 20 min with twoelectrode EC system, while it just took 10 min to achieve the same removal level with bipolar EC system. The result could be attributed to the higher generation rate of aluminum hydroxides 
coagulants for bipolar arrangement of electrodes, which resulted in a fast removal rate of $\mathrm{Zn}^{2+}$ and the effective removal region can be quickly achieved. Based on a shared applied current, fourelectrode arrangement (Figure 3.5b) caused higher voltage than two-electrode arrangement (Figure 3.5a). Thus, the energy consumption will be increased. The optimization of the operational parameters is critical to reduce the cost of EC process when using multiple electrodes. Optimizing the electrode spacing could be an effective way to reduce operation cost due to reduction of applied voltage.

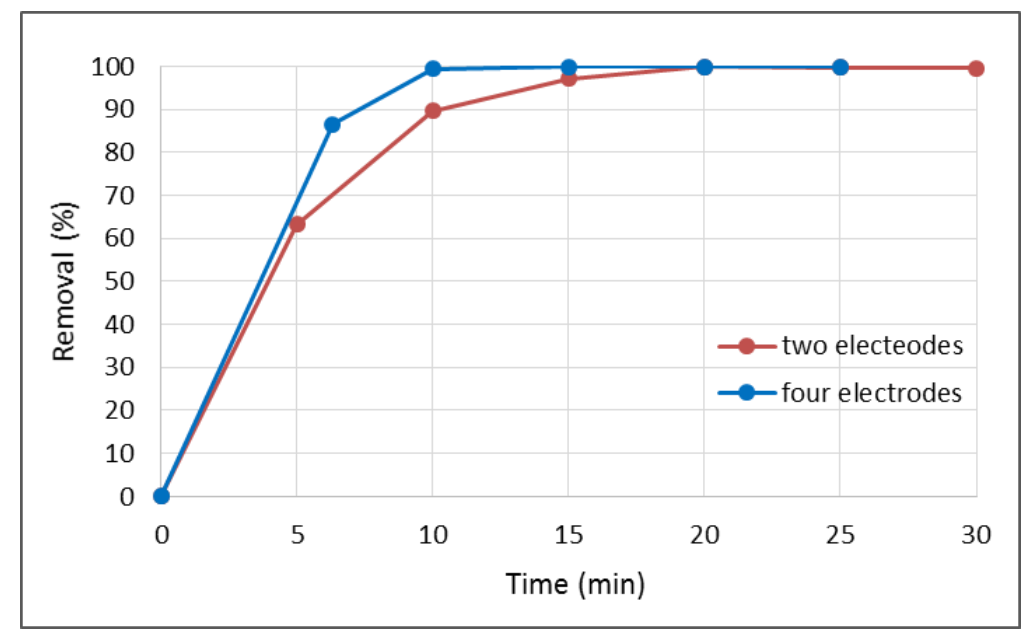

Figure 3.6 Effect of electrodes arrangement on removal of zinc with EC time.

\subsection{Water Matrix Parameters}

\subsubsection{Effect of Solution Conductivity on EC Performance}

In order to improve the performance of EC process for $\mathrm{Zn}^{2+}$ removal, especially in term of the energy consumption, it is necessary to study the effect of solution conductivity on EC process. The original solution conductivities of synthesized model wastewater was $0.15 \mathrm{mS} / \mathrm{cm}$. Sodium chloride $(\mathrm{NaCl})$ was introduced to adjust the solution conductivities. The corresponding conductivities increased from 2.65 to $14.11 \mathrm{mS} / \mathrm{cm}$ when $\mathrm{NaCl}$ does varied from 0.025 to 0.150 $\mathrm{mol} / \mathrm{L}$. 
Figure 3.7 shows the variation of EC voltage during the EC process. It can be seen that the voltage decreased during a short time, after that, reached a pseudo-stationary value. It should be noticed that the duration time required to reach the pseudo-stationary plateau was much longer with lower solution conductivity. In addition, the effect of solution conductivity on pseudo-stationary voltage could be easily observed. When there was no $\mathrm{NaCl}$ addition, the EC voltage was up to $85 \mathrm{~V}$. As conductivity was increased to $2.65 \mathrm{mS} / \mathrm{cm}$, the pseudo-stationary voltage decreased rapidly to 4.7 V. Further increasing conductivity to 9.72 , voltage decreased to $1.8 \mathrm{~V}$. However, an additional increase of conductivity didn't resulte in an effective reduction of the EC voltage. It was well in agreement with the results of other researches (Al-Shannag et al. 2015; Mouedhen et al. 2008). The decrease in EC voltage could be attributed to lower IR-drop due to increasing solution conductivity (Mollah et al. 2004).

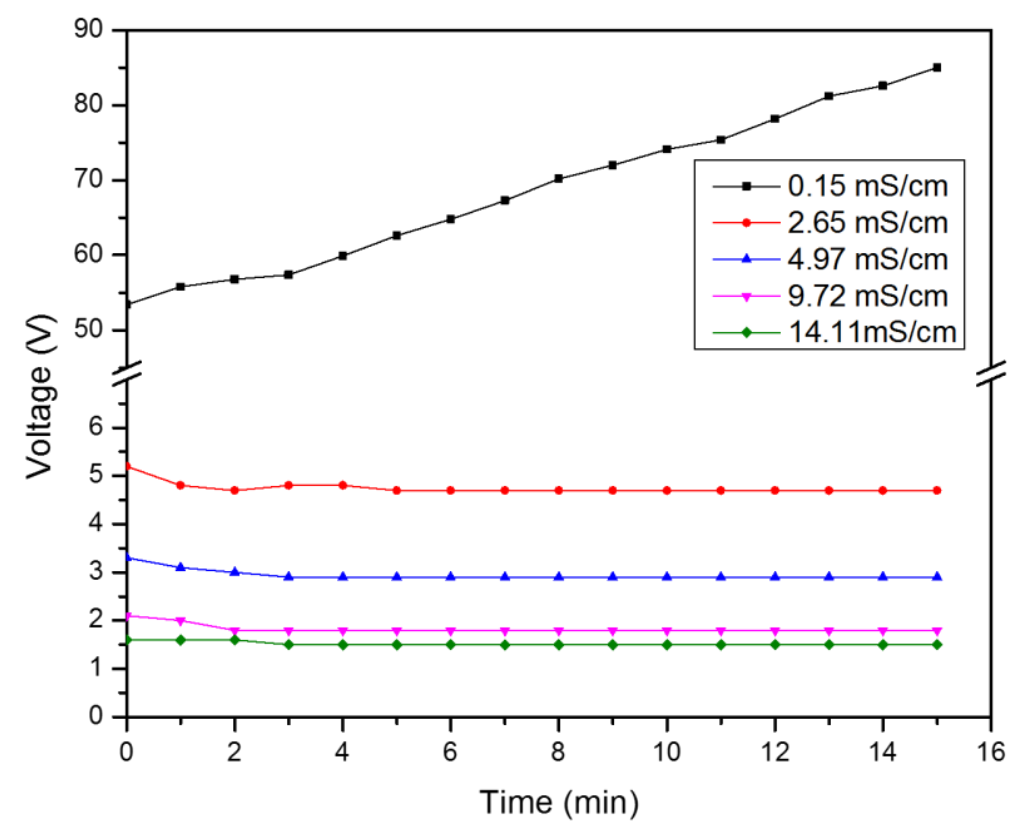

Figure 3.7 Variation of EC voltage during the EC process at different current densities. $\mathrm{C}_{0}=50$ $\mathrm{mg} / \mathrm{L}, \mathrm{CD}=4.2 \mathrm{~mA} / \mathrm{cm}^{2}, \mathrm{~d}=3.0 \mathrm{~cm}, \mathrm{t}=15 \mathrm{~min}, \mathrm{pH}_{\text {initial }}=5.25 \pm 0.03$.

In addition to the benefit of reducing EC voltage, which led to less energy consumption, the solution conductivity also affected the $\mathrm{Zn}^{2+}$ removal. As shown in Figure $3.8,76.7 \% \mathrm{Zn}^{2+}$ was 
removed without $\mathrm{NaCl}$ addition. As solution conductivity increased from 2.65 to $14.11 \mathrm{mS} / \mathrm{cm}$, the $\mathrm{Zn}^{2+}$ removal efficiency improved slightly from 82.3 to $89.0 \%$. This was due to the faster ions migration within the bulk solution at higher solution conductivity, thus, generation of aluminum hydroxides coagulants was accelerated. According to the results of EC voltage and $\mathrm{Zn}^{2+}$ removal efficiency, it could be reasonably concluded that the contribution of solution conductivity on EC performance might be attributed to the reduction of energy consumption. In the present study, it indicated that there was no need to adjust solution conductivity beyond $9.72 \mathrm{mS} / \mathrm{cm}$.

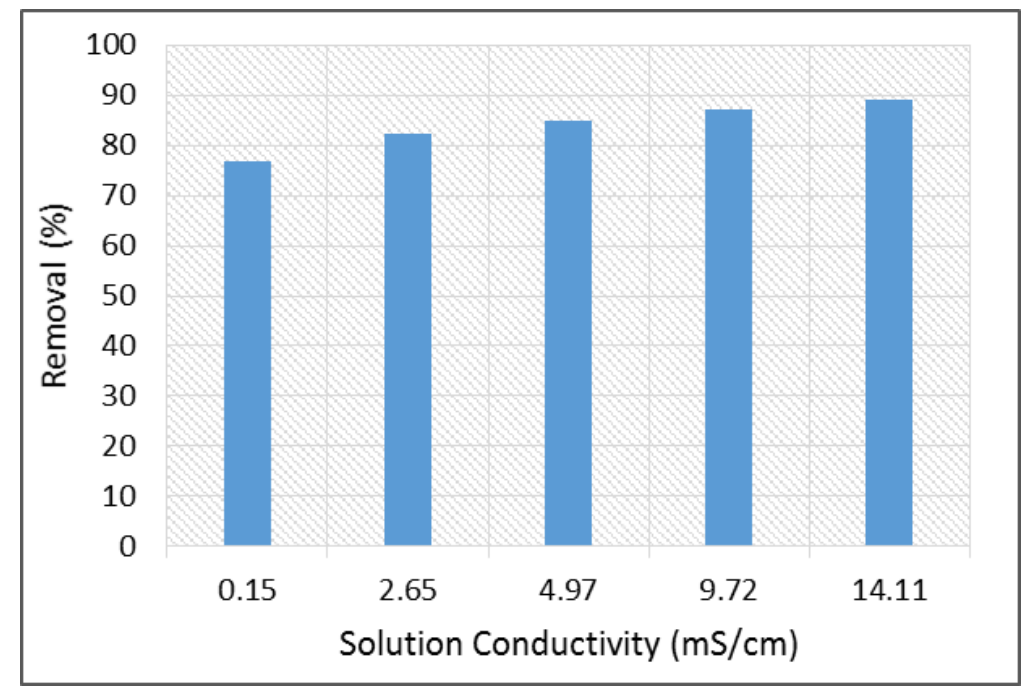

Figure 3.8 Effect of solution conductivity on $\mathrm{Zn}^{2+}$ removal. $\mathrm{C}_{0}=50 \mathrm{mg} / \mathrm{L}, \mathrm{CD}=4.2 \mathrm{~mA} / \mathrm{cm}^{2}$, d $=3.0 \mathrm{~cm}, \mathrm{t}=15 \mathrm{~min}, \mathrm{pH}_{\text {initial }}=5.25 \pm 0.03$.

\subsubsection{Effect of Initial Solution pH on EC Performance}

It is well known that solution $\mathrm{pH}$ is an important factor affecting EC performance. In order to explore the effect behavior of solution $\mathrm{pH}$ on $\mathrm{EC}$, a series of experiments were completed with an initial $\mathrm{pH}$ varying in the range of 2.87-7.38. Figure 3.9 (line graph) shows the bulk solution $\mathrm{pH}$ after EC process versus initial $\mathrm{pH}$. As a general observation, when the initial $\mathrm{pH}$ was acidic, the finial $\mathrm{pH}$ value rose and when the initial was alkaline, final $\mathrm{pH}$ dropped. Accordingly, the aluminum anode was considered to act as a $\mathrm{pH}$ neutralizer (buffering agent) during the EC process (Chen et al. 2004). It was considered that the variation of solution $\mathrm{pH}$ was mainly related to the 
production and consumption of $\mathrm{OH}^{-}$. Moreover, several researchers reported that the $\mathrm{pH}$ has a significant influence on the aluminum species formed during EC process. For acidic $\mathrm{pH}$, monomeric hydrolysis species, such as $\mathrm{Al}^{3+}, \mathrm{Al}(\mathrm{OH})^{2+}$ and $\mathrm{Al}(\mathrm{OH})_{2}{ }^{2+}$, are the major products presented. For $\mathrm{pH}$ around neutrality (between 4 and 9), aluminum hydroxide precipitations are the predominant species. When $\mathrm{pH}$ value is higher than 9, precipitate formation decreases, and monomeric and polymeric aluminum mainly form (Jiménez et al. 2012; Moussa et al. 2017). It is known generation of aluminum hydroxide coagulant mainly located between $\mathrm{pH} 4$ and 9, this fact well explained the variation of $\mathrm{Zn}^{2+}$ removal efficiency at near neutral $\mathrm{pH}$ (3.99-6.5) (Figure 3.9, bar graph). Furthermore, $100 \% \mathrm{Zn}^{2+}$ removal was observed at initial $\mathrm{pH}$ 7.3. However, it should be noticed that the sedimentation of $\mathrm{Zn}^{2+}$ had already occurred before EC treatment by the addition of $\mathrm{NaOH}$ for $\mathrm{pH}$ adjustment. Hence, the effect alkaline $\mathrm{pH}$ was not investigated. As a result, it demonstrated the neutral solution $\mathrm{pH}$ was favorable to reach an effective $\mathrm{Zn}^{2+}$ removal. The further increase of solution $\mathrm{pH}$ beyond 5.25 was not necessary.

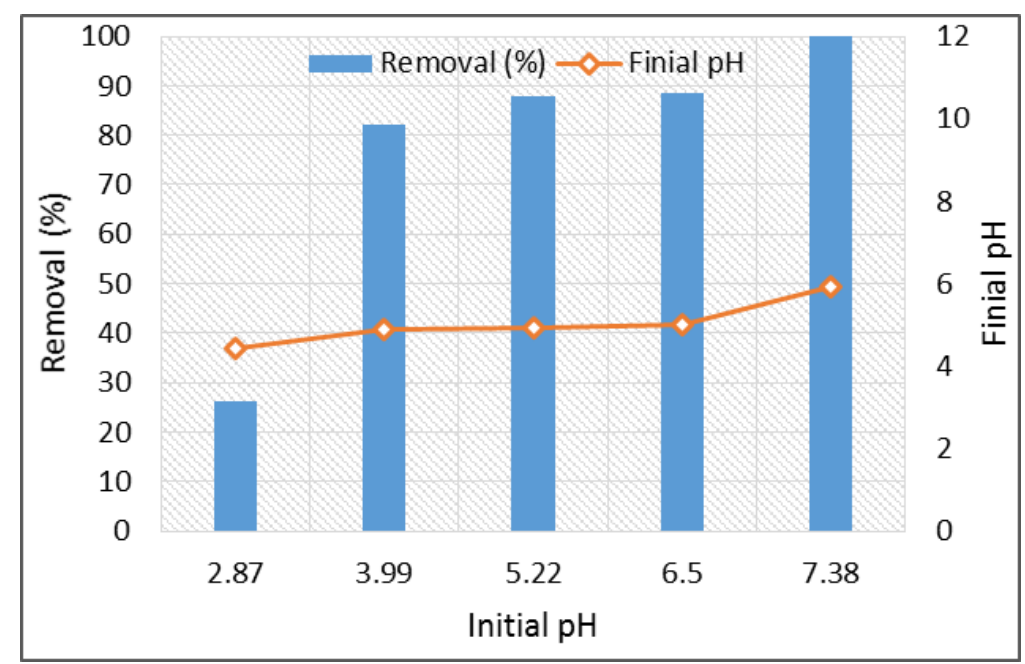

Figure 3.9 Effect of solution $\mathrm{pH}$ on $\mathrm{Zn}^{2+}$ removal. $\mathrm{C}_{0}=50 \mathrm{mg} / \mathrm{L}, \mathrm{CD}=4.2 \mathrm{~mA} / \mathrm{cm}^{2}, \mathrm{~d}=1.0 \mathrm{~cm}$,

$$
\mathrm{t}=15 \mathrm{~min} \text {. }
$$

\subsubsection{Effect of Initial Concentration of Zinc on EC Performance}


EC treatment for different initial concentrations $(50-2,000 \mathrm{mg} / \mathrm{L})$ was performed. Figure 3.10 shows the variation of residual $\mathrm{Zn}^{2+}$ concentrations for different initial concentrations as a function of time at the current density of $8.3 \mathrm{~mA} / \mathrm{cm}^{2}$. Generally observing, the graphs for initial concentrations from 250-2,000 mg/L exhibited a similar trend (slope depending) related with time. It implied removal rates were not affected by initial concentrations, which was consistent with the results in previous studies (Heidmann et al. 2010; Al Aji et al. 2012) The different trend observed at lower initial concentrations $(50,100 \mathrm{mg} / \mathrm{L})$ might be related with the precipitation kinetics of metallic hydroxides. In addition, as shown in Figure 3.10, for higher initial $\mathrm{Zn}^{2+}$ concentrations, longer EC time was required to get an effective treatment. The EC treatment was more effective at the beginning of the $\mathrm{EC}$ process when $\mathrm{Zn}^{2+}$ concentration was higher, followed by a slower removal rate when the $\mathrm{Zn}^{2+}$ concentration was relatively lower.

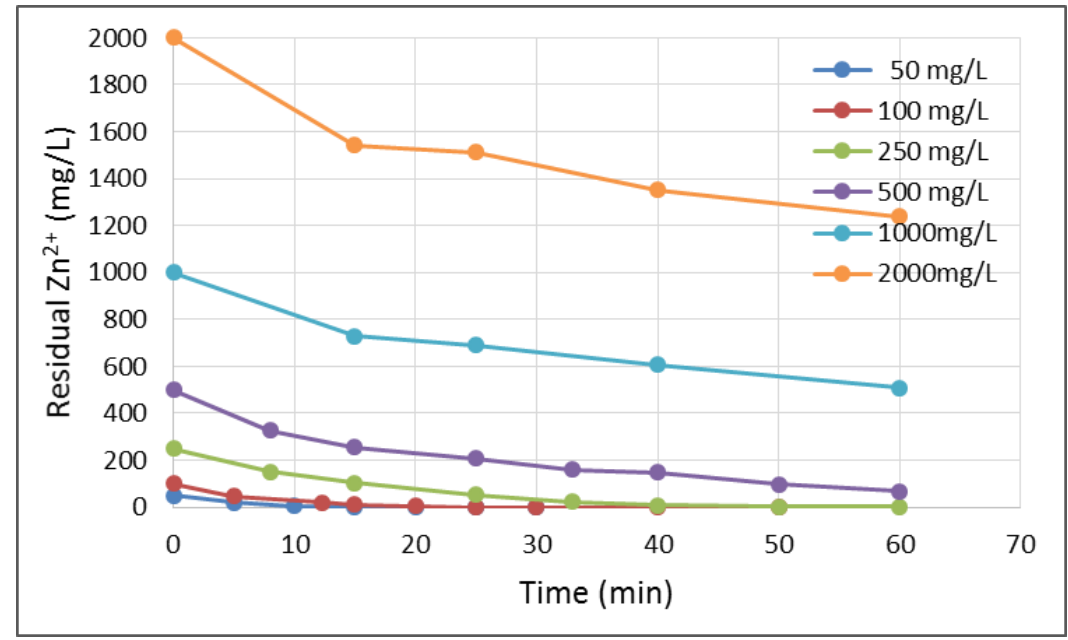

Figure 3.10 Effect of initial $\mathrm{Zn}^{2+}$ concentration on $\mathrm{Zn}^{2+}$ removal. Initial concentrations were 50, $100,250,500,1,000$ and 2,000 $\mathrm{mg} / \mathrm{L} . \mathrm{CD}=8.3 \mathrm{~mA} / \mathrm{cm}^{2}, \sigma=9.7 \mathrm{mS} / \mathrm{cm}, \mathrm{d}=1.0 \mathrm{~cm}$.

\subsection{Water Matrix Composition}

\subsubsection{Removal of Strontium by EC}

Based on zinc results, strontium ion removal by EC also has been studied in this work. Figure 3.11 
shows effect of current density on strontium removal efficiency. EC processes were performed for one hour at current density of 2.1, 4.2, 8.3 and $12.5 \mathrm{~mA} / \mathrm{cm}^{2}$, respectively. It was observed that increasing current density improved the strontium removal efficiency. But compared with the $\mathrm{Zn}^{2+}$ removal, the removal efficiency of strontium ion is relatively lower at the same current density. It was believed that the low current efficiency took place during EC process. As a result of the lower current efficiency, the applied current density should stay above $4.2 \mathrm{~mA} / \mathrm{cm}^{2}$ to maintain the removal effectiveness.

It was reported that the initial solution $\mathrm{pH}$ is an influential factor for strontium removal (Kamaraj et al. 2015). Experiments were completed at initial solution $\mathrm{pH}$ of 3.5, 5.6 and 7.5. As shown in Figure 3.12, the change of initial $\mathrm{pH}$ barely impacted removal efficiency. It is unnecessary to adjust the initial $\mathrm{pH}$ of model wastewater to improve the EC performance.

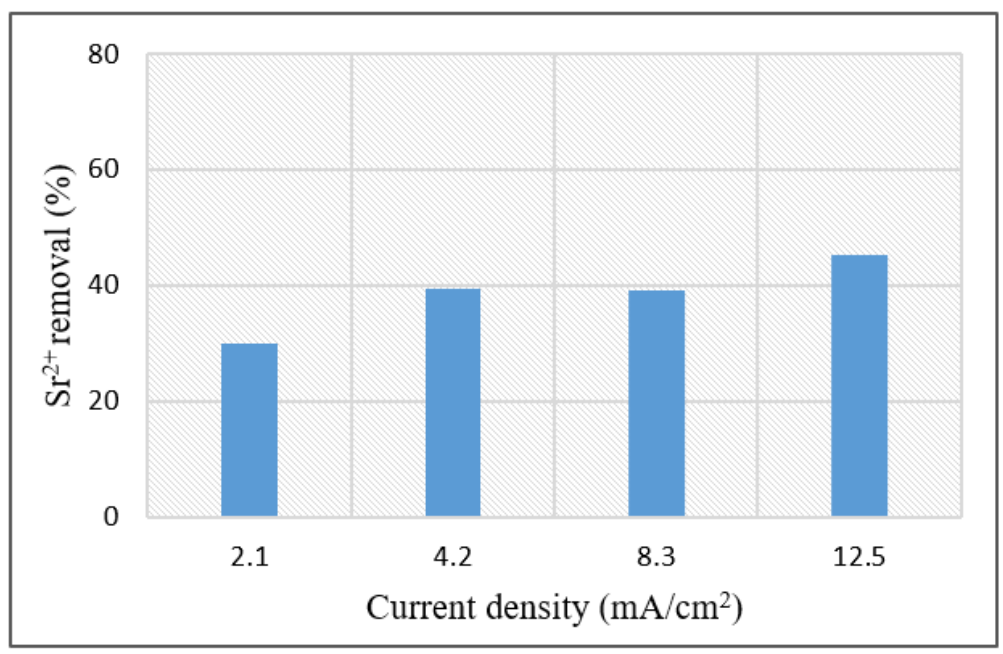

Figure 3.11 Effect of current density on the removal of strontium ions. Applied current: $0.05-$ $0.3 \mathrm{~A}, \mathrm{C}_{0}=10 \mathrm{mg} / \mathrm{L}, \sigma=9.72 \mathrm{mS} / \mathrm{cm}, \mathrm{d}=1.0 \mathrm{~cm}, \mathrm{t}=60 \mathrm{~min}$.

Figure 3.13 shows the variation of removal efficiency as a function of different electrode spacing. It can be clearly seen that the relatively high removal efficiency of strontium was achieved at a low electrode spacing of $5 \mathrm{~mm}$. It is resulted from a faster formation rate of coagulants under a localized combination of aluminum and hydroxide ions with a low electrode spacing. The relative 
high removal efficiency of strontium also can be achieved at the electrode spacing of $30 \mathrm{~mm}$. This result could be explained by the decrease of formed electrostatic filed as increasing electrode spacing, leading to a slower migration of the ions produced during the EC process and facilitating the flocculation of coagulants, which eventually makes the removal of zinc ions by aluminum hydroxides flocs more efficient (Nanseu-Njiki et al. 2009).

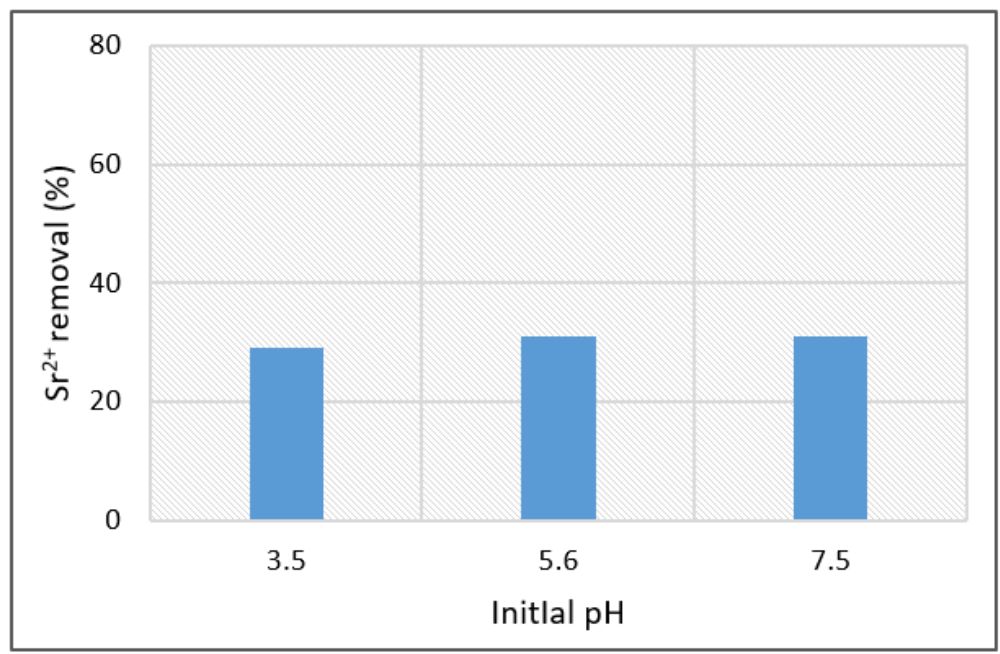

Figure 3.12 Effect of initial $\mathrm{pH}$ on the removal of strontium ions. $\mathrm{CD}=2.1 \mathrm{~mA} / \mathrm{cm}^{2}, \mathrm{C}_{0}=10$ $\mathrm{mg} / \mathrm{L}, \mathrm{d}=1.0 \mathrm{~cm}, \mathrm{t}=30 \mathrm{~min}$.

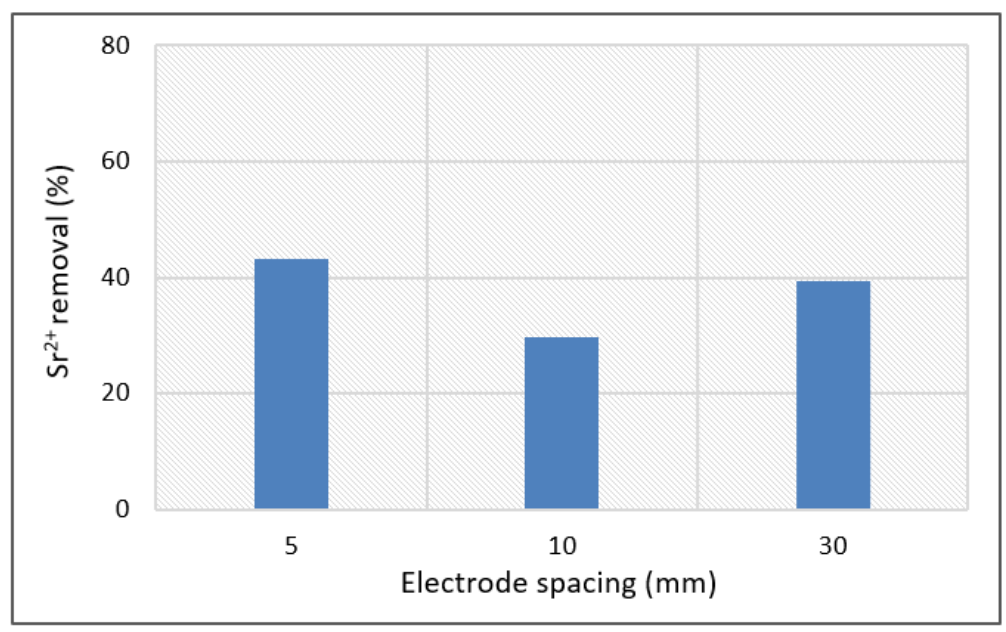

Figure 3.13 Effect of electrode spacing on the removal of strontium ions. $\mathrm{CD}=8.3 \mathrm{~mA} / \mathrm{cm}^{2}, \mathrm{C}_{0}$ $=10 \mathrm{mg} / \mathrm{L}, \sigma=9.72 \mathrm{mS} / \mathrm{cm}, \mathrm{t}=30 \mathrm{~min}$. 


\subsubsection{Mixed Contaminant Removal ( $\mathrm{Zn}, \mathrm{Cu}, \mathrm{Fe}, \mathrm{Mn}, \mathrm{Mg}, \mathrm{Ca}, \mathrm{Ba}$ and $\mathrm{Sr})$}

Typical wastewater contain multiple metal contaminants. Therefore, multi-metal system should be designed as the model wastewater rather than the single-metal system. Given one specific targeted metal, the presence of others can significantly affect the selective removal. Three multi-metal systems (M-A, M-B, and M-C) were employed as the model wastewater in this work. Table 3.1 shows the concentration of existing metals.

Table 3.1 Mixed contaminant and concentrations in multi-metal system.

\begin{tabular}{c|cccc|cc|cccc}
\hline & \multicolumn{4}{|c|}{ M-A } & \multicolumn{3}{c|}{ M-B } & \multicolumn{4}{c}{ M-C } \\
\hline Metals & $\mathrm{Fe}$ & $\mathrm{Cu}$ & $\mathrm{Zn}$ & $\mathrm{Mn}$ & $\mathrm{Zn}$ & $\mathrm{Sr}$ & $\mathrm{Ba}$ & $\mathrm{Ca}$ & $\mathrm{Mg}$ & $\mathrm{Sr}$ \\
Conc. (mg/L) & 25.00 & 25.00 & 25.00 & 25.00 & 10.00 & 10.00 & 249.15 & 729.73 & 316.07 & 1760.22 \\
\hline
\end{tabular}

Figure 3.14 shows the removal of $\mathrm{Fe}^{3+}, \mathrm{Cu}^{2+}, \mathrm{Zn}^{2+}$ and $\mathrm{Mn}^{2+}$ by EC process in the mixed solution M-A. These four metals competed for hydroxide ions produced at the cathode and sorption sites at aluminum hydroxide surface. The precipitation of Fe should be the priority due to its lowest solubility as iron hydroxide compared with the other metals. At 15 min of EC process, the removal efficiency of Fe was almost two times of $\mathrm{Zn}$. The formed iron hydroxide acted as new coagulant, which was similar to aluminum hydroxide. The presence of this new coagulant could promote the precipitation of $\mathrm{Cu}$ and $\mathrm{Zn}$. The real wastewater from rivers often contains $\mathrm{Mg}$. $\mathrm{Ca}, \mathrm{Sr}$ and $\mathrm{Ba}$, among which Sr has the highest concentration. So the mixed solution M-B was designed as model wastewater to compare $\mathrm{Sr}$ with $\mathrm{Zn}$ (as control). As shown in Figure 3.15, 99\% zinc was removed in less than 10 min while only $38 \%$ strontium was removed. The residual strontium can hardly be removed after $10 \mathrm{~min}$. It has implied that different removal mechanisms might exist. 


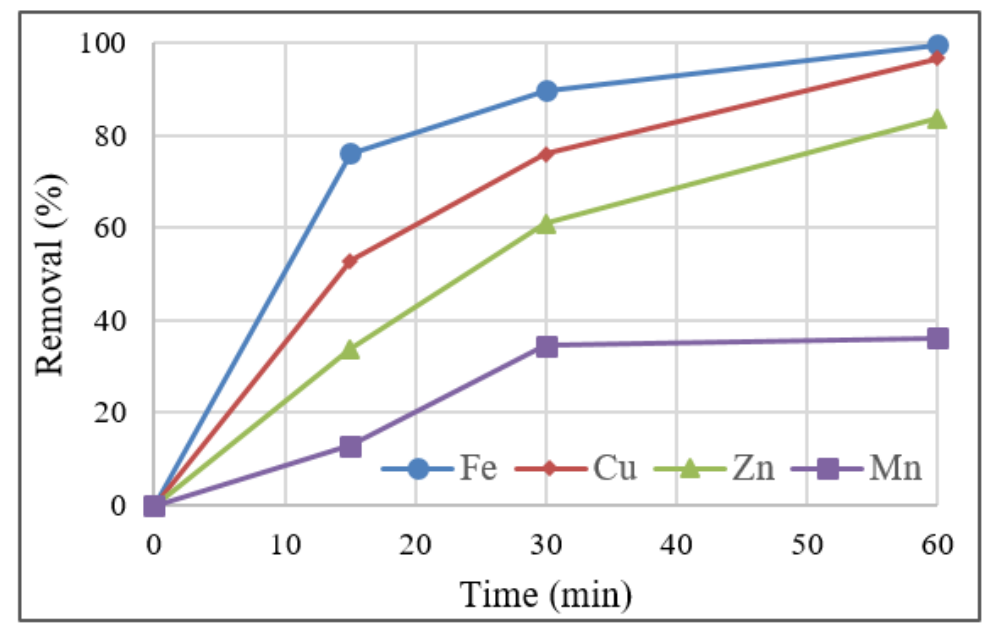

Figure 3.14 Removal efficiency of $\mathrm{Fe}, \mathrm{Cu}, \mathrm{Zn}$, and $\mathrm{Mn}$ ions during EC with model wastewater M-A. $\mathrm{CD}=2.1 \mathrm{~mA} / \mathrm{cm}^{2}, \mathrm{pH}_{\text {initial }}=4.0$.

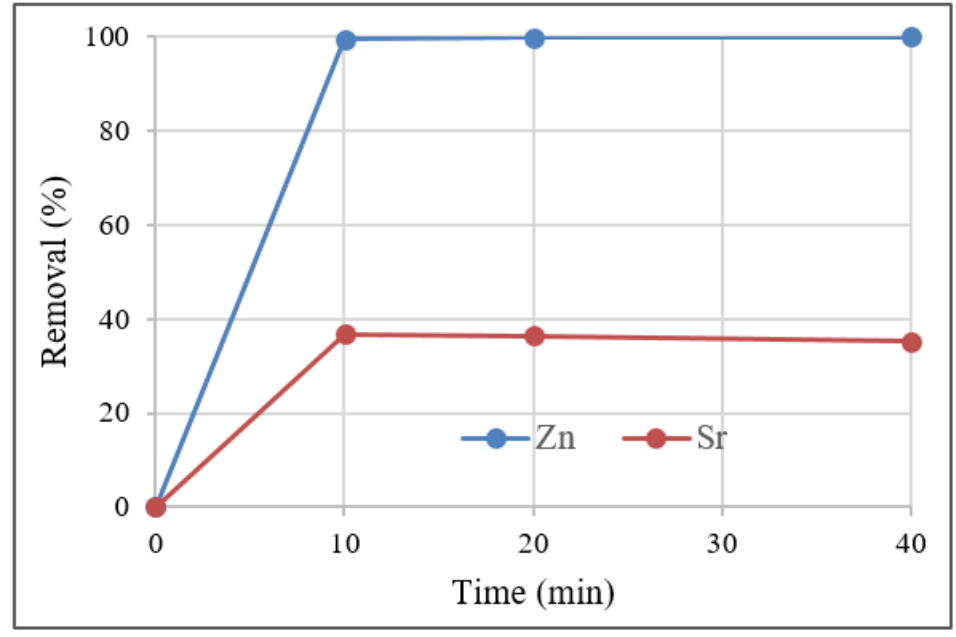

Figure 3.15 Evolution of metals removal efficiency versus EC time during EC process with model wastewater M-B. CD $=4.2 \mathrm{~mA} / \mathrm{cm}^{2}$.

In order to further simulate the river wastewater, the mixed solution $\mathrm{M}-\mathrm{C}$ was designed. Figure 3.16 shows the amount of removed $\mathrm{Ba}, \mathrm{Ca}, \mathrm{Mg}$ and $\mathrm{Sr}$ from system $\mathrm{M}-\mathrm{C}$ at current density of 4.2 and $8.3 \mathrm{~mA} / \mathrm{cm}^{2}$. These four elements belong to the same periodic group. The removal easiness goes by $\mathrm{Mg}>\mathrm{Ca}>\mathrm{Sr}>\mathrm{Ba}$. It was observed $\mathrm{Mg}$ exhibited the highest removal, while $\mathrm{Ba}$ and $\mathrm{Sr}$ could hardly be removed during EC process, despite of the higher current density. It could be explained by the higher solubility of $\mathrm{Sr}$ and $\mathrm{Ba}$ hydroxides than that of $\mathrm{Mg}$ and $\mathrm{Ca}$. Besides, it is believed that $\mathrm{Mg}$ was easily removed via the co-precipitation with $\mathrm{Al}(\mathrm{OH})_{3}$, which resulted from 
their similar atomic diameters of $\mathrm{Al}$ and $\mathrm{Mg}$. Additionally, it can be found that the higher current density led to a lower removal efficiency of $\mathrm{Mg}$. The similar result was also reported by other researchers and the lower reaction kinetics and concentration overpotential were commonly considered as the reasons (Mollah et al. 2001). Theoretically, many believe that the removal efficiency of metal ions is related to current density. For example, a higher current density in a certain range could result in a quicker removal rate because of stimulated coagulation and bubbles generation. However, the optimum current density for this case might not locate in the range of 4.2 and $8.3 \mathrm{~mA} / \mathrm{cm}^{2}$. Acceleration of EC process is not beneficial for the removal of these metal ions. It is necessary to find out a current density more effective in our future work to treat wastewater.

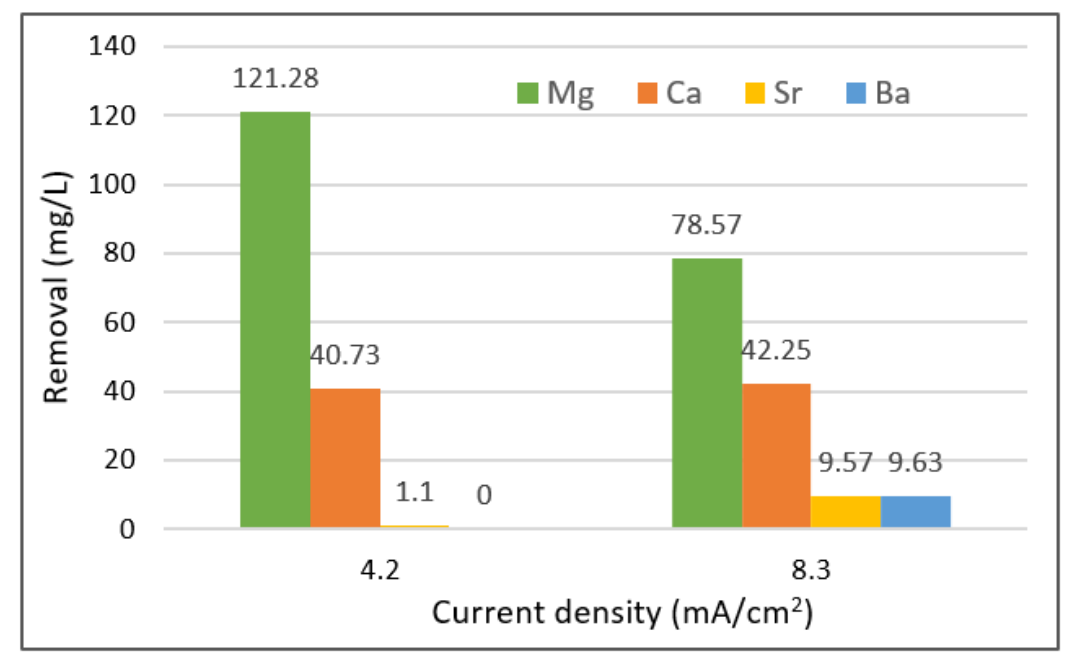

Figure 3.16 Removed $\mathrm{Mg}, \mathrm{Ca}, \mathrm{Sr}$ and $\mathrm{Ba}$ ions after 30 min EC process with model wastewater M-C at different current densities.

\subsection{Energy consumption}

Electrical energy consumption plays an important role in the electrocoagulation process for wastewater treatment, which is directly related to the current density. The electrical energy consumption per volume of the treated wastewater can calculated by Eq. 20. Figure 3.17 shows the variation of energy consumption and required EC time with current densities. As we can see, 
energy consumption for $96 \%$ removal of zinc ions was about $0.097,0.13,0.25$ and $0.30 \mathrm{kWh} / \mathrm{m}^{3}$, with current density of 2.1, 4.2, 8.3 and $12.5 \mathrm{~mA} / \mathrm{cm}^{2}$, respectively. For $99 \%$ removal of zinc, the energy consumption was $0.11,0.17,0.35$ and $0.45 \mathrm{kWh} / \mathrm{m}^{3}$, respectively. The energy consumption increased significantly with increasing current density. Meanwhile, the required EC time reduced with current density above $4.2 \mathrm{~mA} / \mathrm{cm}^{2}$. It clearly suggests the current density should not be less than $4.2 \mathrm{~mA} / \mathrm{cm}^{2}$ for wastewater treatment with zinc ions concentration of $50 \mathrm{mg} / \mathrm{L}$. Moreover, it can be observed that more energy consumed at higher current density when removal efficiency increased from $96 \%$ to $99 \%$. It indicates that the complete removal of zinc ions could be achieved at lower current density with less energy consumption.

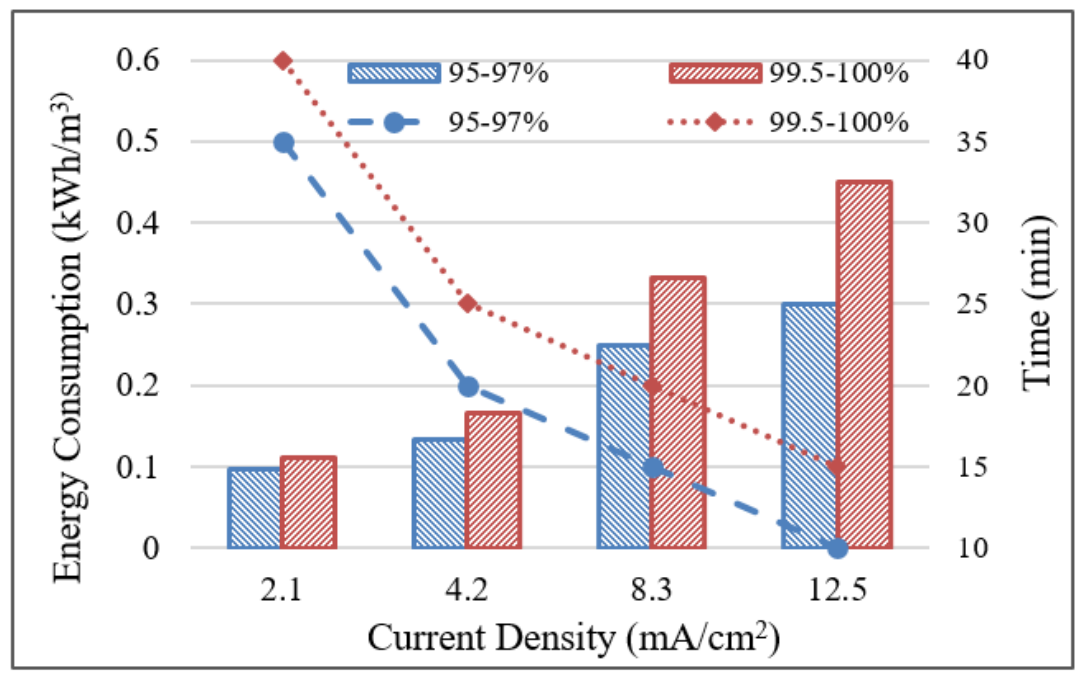

Figure 3.17 Variation of energy consumption (bar graph) and required EC time (line graph) as a function of current densities for two levels of removal percentages 95-97\% and 99.5-100\%. $\mathrm{C}_{0}$ $=50 \mathrm{mg} / \mathrm{L}$.

\section{Kinetic Study and Removal Mechanism}

\subsection{Kinetic Modeling}

In the present work, beside the experimental result, the kinetic study for zinc removal was performed to describe the adsorption system during EC process at different densities and initial 
concentrations. Three kinetic models, including first-order, pseudo-first order were applied to the obtained results based on the solution concentration. For the present EC process, the mass conservation of heavy metal ions can be generally expressed as (Bazrafshan et al. 2012):

$-\frac{d C}{d t}=(-r)$

Where $C_{t}(\mathrm{ppm})$ is the concentration at EC time $\mathrm{t}(\mathrm{min})$, and (-r) (ppm/min) is the removal rate of metal ions. For the first- order model, $(-r)$ is given as $\left(-K_{1} C_{t}\right)$, where $K_{1}$ is the first order constant. So the formula (Eq. 21) can be integrated with the boundary conditions of $t=0$ to $t=t$ and $C_{t}=C_{0}$ to $\mathrm{C}_{\mathrm{t}}=\mathrm{C}_{\mathrm{t}}$ to yield:

$\ln \mathrm{C}_{\mathrm{t}}=-\mathrm{K}_{1} \mathrm{t}+\ln \mathrm{C}_{0}$

and simplified as:

$\mathrm{C}_{\mathrm{t}}=\mathrm{C}_{0} \mathrm{e}^{-\mathrm{K} 1 \mathrm{t}}$

For the pseudo-first order model, the adsorption equilibrium was introduced to describe the adsorption rate, $(-r)=K_{p}\left(C_{t}-C_{e}\right)$, the adsorption rate is proportional to the concentration gradient at time $\mathrm{t}$ and at equilibrium. The integration form of pseudo-first order model with boundary conditions $\mathrm{t}=0$ to $\mathrm{t}=\mathrm{t}$ and $\mathrm{C}_{\mathrm{t}}=\mathrm{C}_{0}$ to $\mathrm{C}_{\mathrm{t}}=\mathrm{C}_{\mathrm{t}}$ is rearranged as:

$\mathrm{C}_{\mathrm{t}}=\mathrm{C}_{\mathrm{e}}+\left(\mathrm{C}_{0}-\mathrm{C}_{\mathrm{e}}\right) \mathrm{e}^{-\mathrm{Kp}}$

Where $\mathrm{C}_{\mathrm{e}}(\mathrm{mg} / \mathrm{L})$ is the concentration of metal ions at equilibrium, and $\mathrm{K}_{\mathrm{p}}$ is the rate constant of pseudo-first order adsorption. Accordingly, if the equilibrium concentration is extremely low, even zero value, the pseudo-first order model is not suitable for describing the adsorption process, and the adsorption model will be back to the first order model.

For the second order model, (-r) is given as $\left(\mathrm{K}_{2}\left(\mathrm{C}_{\mathrm{e}}-\mathrm{C}_{\mathrm{t}}\right)^{2}\right)$, where $\mathrm{K}_{2}$ is the rate constant of secondorder adsorption. With the boundary conditions $t=0$ to $t=t$ and $C_{t}=C_{0}$ to $C_{t}=C_{t}$, the second-order model can be expressed as:

$\mathrm{t} / \mathrm{C}_{\mathrm{t}}=1 /\left(\mathrm{K}_{2} \mathrm{C}_{\mathrm{e}}{ }^{2}\right)+\mathrm{t} / \mathrm{C}_{\mathrm{e}}$

(Eq. 25)

\subsubsection{Kinetic Modelling at Different Current Densities}


The correlation coefficients $\left(\mathrm{R}^{2}\right)$ of second-order model $(0.34732 \sim 0.86556)$ at all conditions were much lower than the unity. Obviously, the removal of zinc ions in present case cannot be modelled by the second-order absorption. Table 4.1 shows the kinetic parameters for first-order and pseudofirst order model at different current densities. It can be seen that great $\mathrm{R}^{2}$ values obtained both in first-order and pseudo-first order models. However, the theoretical $\mathrm{C}_{\mathrm{e}}$ values obtained from pseudo-first order model were minus, strongly disagree to the experimental $\mathrm{C}_{\mathrm{e}}$ (exp.) values, which were even zero at all current densities (Figure 4.1, marked as dots). This disagree behavior was in agreement with the issues discussed above, if the equilibrium concentration is extremely low, even close to zero value, the pseudo-first order model gets back to the first-order model. Figure 4.1 also displays the first-order curves strongly fitted the experimental concentrations, which further demonstrated that the first-order model is more qualified than pseudo-first order model in analyzing the removal rates of zinc ions at different current densities. It can be observed that the first-order rate constant $\mathrm{K}_{1}$ increased with increasing of current density. For instance, when the current density was $2.1,4.2,8.3$ and $12.5 \mathrm{~mA} / \mathrm{cm}^{2}$, the corresponding $\mathrm{K}_{1}$ was $0.0833,0.14775$, 0.21087 and 0.30142 , respectively. This result strongly agreed with the experiment result, suggesting that increase of current density resulted in the acceleration of zinc removal process.

Table 4.1 The kinetic parameters for first-order and pseudo-first order model at different current densities.

\begin{tabular}{cccccc}
\hline Current density & \multicolumn{2}{c}{ First order model } & \multicolumn{3}{c}{ Pseudo-first order model } \\
\hline $\mathbf{m A} / \mathbf{c m}^{\mathbf{2}}$ & $\mathrm{K}_{1}\left(\mathrm{~min}^{-1}\right)$ & $\mathrm{R}^{2}$ & $\mathrm{C}_{\mathrm{e}}$ & $\mathrm{K}_{1}\left(\mathrm{~min}^{-1}\right)$ & $\mathrm{R}^{2}$ \\
$\mathbf{2 . 1}$ & 0.0833 & 0.97912 & 0.0449 & 0.10926 & 0.98756 \\
$\mathbf{4 . 2}$ & 0.14775 & 0.99463 & -0.554 & 0.14312 & 0.99387 \\
$\mathbf{8 . 3}$ & 0.21087 & 0.99868 & -0.5129 & 0.20458 & 0.99887 \\
$\mathbf{1 2 . 5}$ & 0.30142 & 0.99956 & -0.15781 & 0.29825 & 0.99991 \\
\hline
\end{tabular}




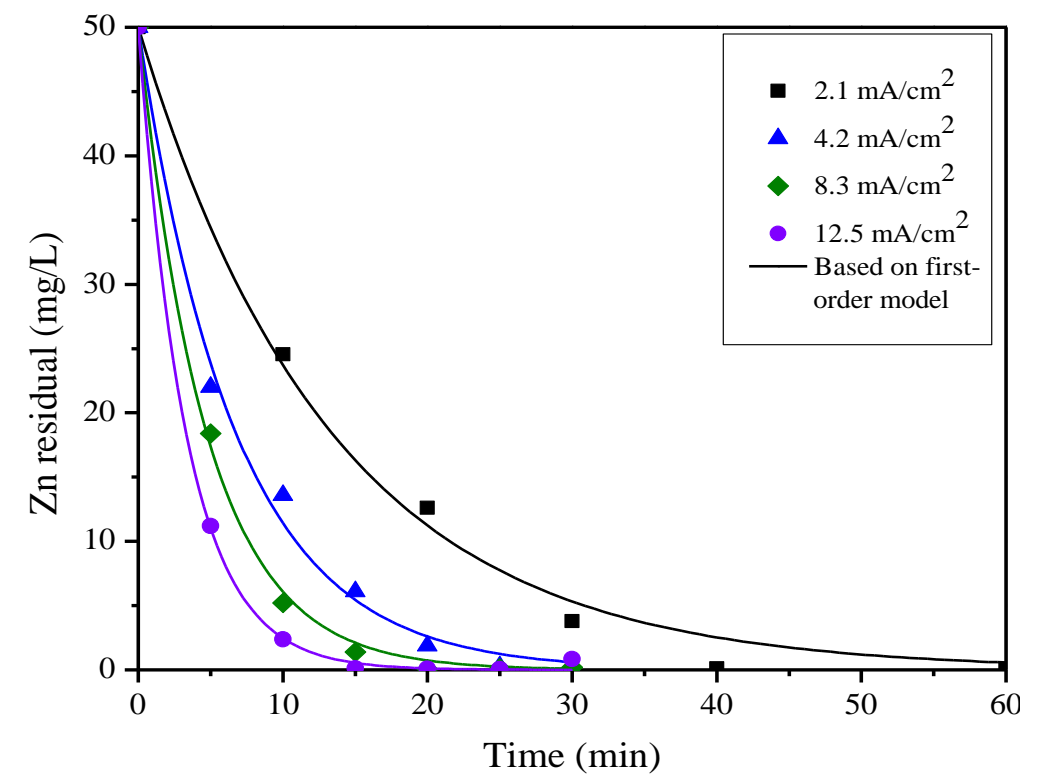

Figure 4.1 Variation of residual zinc concentrations during EC process at different current densities. The solid lines are fitted curves based on first-order model.

\subsubsection{Kinetic Modelling at Different Initial Concentrations}

Table 4.2 shows related kinetic parameters for first-order and pseudo-first order model at different concentrations. The $\mathrm{R}^{2}$ values obtained from first order model decreased with increasing initial concentration, which indicated that the removal of zinc ions fitted better with the first order model at related low concentration $(50,100$ and $250 \mathrm{mg} / \mathrm{L})$. For the pseudo-first order model, as can be observed that the equilibrium $\mathrm{C}_{\mathrm{e}}$ values strongly matched the corresponding experimental values at initial concentration 500, 1,000 and 2,000 mg/L (Figure 4.2), and the $\mathrm{R}^{2}$ values were also more close to unity. It was clearly demonstrated that the pseudo-first order model is a better representation of zinc removal at high concentrations.

Moreover, it was observed from Table 4.2 that the removal rate of zinc ions decreased with increasing initial concentration, it means more charge loading was required to reach the equilibrium concentrations. However, when the initial concentration increased up to around 250 $\mathrm{mg} / \mathrm{L}$, the rate constant tended to be constant. It indicated that the amount of zinc delivered by per 
unit of aluminum is not affected by the zinc initial concentration, which was well in agreement with the speculation for the results of Figure 3.10. Furthermore, it was noticed the rate constant at $2,000 \mathrm{mg} / \mathrm{L}$ is larger than that one at $1,000 \mathrm{mg} / \mathrm{L}$. Meanwhile, the obvious deposition layer was found on the cathode surface after the corresponding EC experiment at the initial concentration $2,000 \mathrm{mg} / \mathrm{L}$. It could be reasonably speculated that there was another path related to this deposition layer, which might be the reduction product of zinc at cathode surface.

Table 4.2 The kinetic parameters for first-order and pseudo-first order model at different initial concentrations.

\begin{tabular}{cccccc}
\hline Initial conc. & \multicolumn{2}{c}{ First order model } & \multicolumn{3}{c}{ Pseudo-first order model } \\
\hline $\mathbf{m g} / \mathrm{L}$ & $\mathrm{K}_{1}\left(\mathrm{~min}^{-1}\right)$ & $\mathrm{R}^{2}$ & $\mathrm{C}_{\mathrm{e}}$ & $\mathrm{K}_{1}\left(\mathrm{~min}^{-1}\right)$ & $\mathrm{R}^{2}$ \\
$\mathbf{5 0}$ & 0.21087 & 0.99868 & -0.5129 & 0.20458 & 0.99887 \\
$\mathbf{1 0 0}$ & 0.14848 & 0.9983 & -0.68998 & 0.14534 & 0.99827 \\
$\mathbf{2 5 0}$ & 0.06486 & 0.99426 & -12.32778 & 0.05747 & 0.99755 \\
$\mathbf{5 0 0}$ & 0.03619 & 0.96677 & 0.99755 & 0.05199 & 0.9811 \\
$\mathbf{1 0 0 0}$ & 0.01304 & 0.90758 & 481.70668 & 0.04072 & 0.97532 \\
$\mathbf{2 0 0 0}$ & 0.00962 & 0.84684 & 1213.02075 & 0.04663 & 0.97029 \\
\hline
\end{tabular}




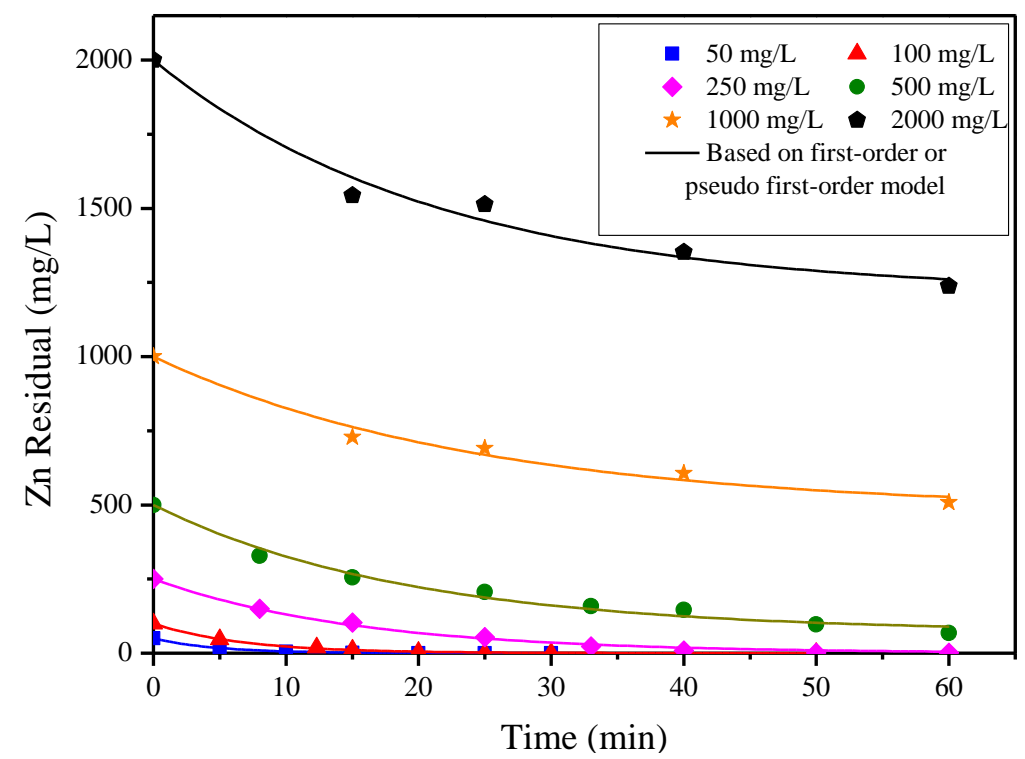

Figure 4.2 Variation of both experimental and first-order concentrations versus time at different initial concentrations. The solid lines are fitted curves based on first-order model (at 50, 100 and $250 \mathrm{mg} / \mathrm{L}$ ) and pseudo first-order model (at 500, 1000 and $2000 \mathrm{mg} / \mathrm{L}$ ).

\subsection{Removal Mechanism}

\subsubsection{Controls}

A series of control experiments were completed with zinc initial concentration $250 \mathrm{mg} / \mathrm{L}$. As shown in Figure 4.3, during the experiment, the anode is made of aluminum (a), the carbon electrode as anode in the attempts (b) and (c). In addition, aluminum sulfate was added in the model wastewater for the experiment (c). According to Faraday's Law, a pre-determined amount of $\mathrm{Al}^{3+}$ equal to the theoretical value was dissolved by aluminum anode in the experiment (a). From Table 4.3, it can be seen that the removal efficiencies are 96, 51, 22\% for the experiment (a), (b) and (c), respectively. When the aluminum was used as anode, the zinc was mainly removed by adsorption of aluminum hydroxide flocs. When carbon was used as the anode, zinc was mainly removed by precipitation of zinc hydroxide. Because of $\mathrm{Al}^{3+}$ added in electrolyte, it will compete with hydroxide ions with zinc, leading to a low removal efficiency of zinc ions. When compared the results of experiment (a) with (c), it indicated the high adsorption efficiency of in-situ generated aluminum hydroxide. Flocs formed by EC are similar to chemical flocs, except for a larger size 
and less bound water. EC flocs has better performance to aggregate the colloidal particles. Therefore, it is believed that the metal can be better precipitated by the EC flocs. The formed precipitation can then be easily removed by filtration.

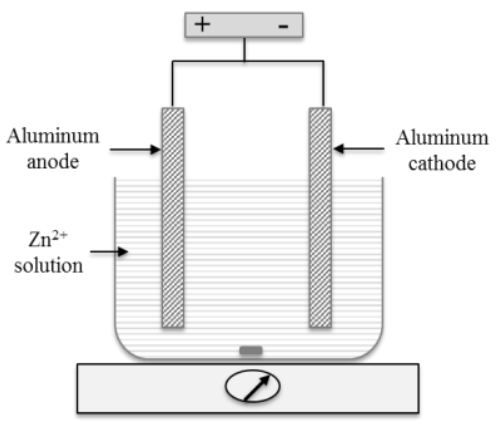

(a)

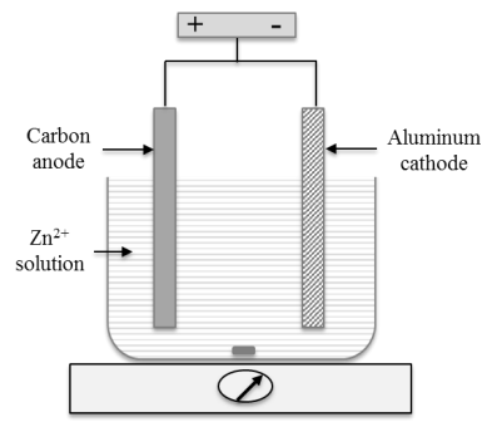

(b)

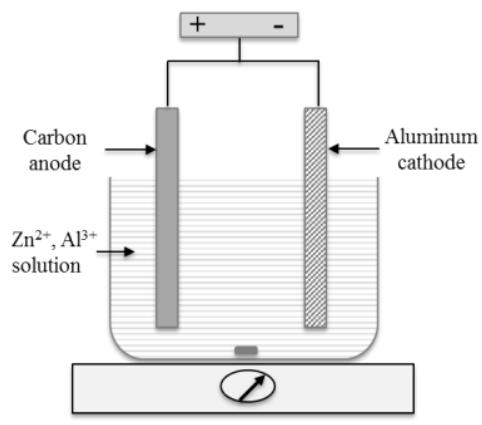

(c)

Figure 4.3 Schematic diagrams of control experimental setup: (a) aluminum anode, (b) carbon anode, (c) carbon anode, in the presence of $\mathrm{Al}^{3+} . \mathrm{C}_{0}=250 \mathrm{mg} / \mathrm{L}, \mathrm{CD}=8.3 \mathrm{~mA} / \mathrm{cm}^{2}, \mathrm{~d}=1.0 \mathrm{~cm}$.

Table 4.3 The corresponding results obtained by the control experiments.

\begin{tabular}{cccc}
\hline Anode-Cathode & Metal ions & Zn Removal (\%) & Precipitation Observed \\
\hline (a) $\mathrm{Al}-\mathrm{Al}$ & $\mathrm{Zn}^{2+}$ & 96 & Very much \\
(b) $\mathrm{C}-\mathrm{Al}$ & $\mathrm{Zn}^{2+}$ & 51 & Rare \\
(c) $\mathrm{C}-\mathrm{Al}$ & $\mathrm{Zn}^{2+}, \mathrm{Al}^{3+}$ & 22 & Some \\
\hline
\end{tabular}

\subsubsection{Characteristic of the By-products of EC Process}

In order to further investigate the possible reaction during EC process, the zinc was traced down after EC treatment. Besides the residual zinc remained in solution after filtration, the removed zinc could be contained in two parts, as shown in Figure 4.4. One is the precipitation filtered from solution, it is considered as the product containing aluminum hydroxide flocs and the precipitated zinc. The other part might contain zinc is the deposition layer formed at the cathode surface, especially with high initial concentration of zinc. 


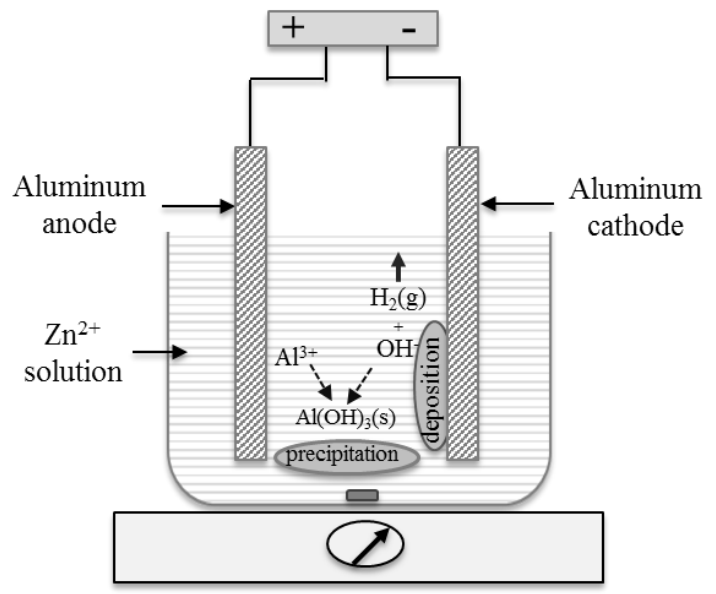

Figure 4.4 Schematic diagram of products produced during EC process.

For the sake of further understanding the morphology and chemical composition of this formed precipitation and deposition, SEM, EDX and XRD analyses were performed. It was found from SEM images that the precipitation has a gel like consistency (Figure 4.5 left). EDX result shows the products is composed of $\mathrm{O}, \mathrm{Na}, \mathrm{Al}$ and $\mathrm{Cl}$ (Figure 4.5 right). No Zinc was detected. It might due to the amount of zinc is too low. So the precipitation was dissolved using nitric acid, then analyzed using ICP. The obtained ICP results are shown in Table 4.4. When the initial concentration of zinc is $500 \mathrm{mg} / \mathrm{L}, 431.809 \mathrm{mg} / \mathrm{L}$ was removed after $60 \mathrm{~min}$ of EC treatment (calculated by the residual concentration left in solution after filtration). Among the removed zinc, $323.614 \mathrm{mg} / \mathrm{L}$ was present in the precipitation product accounting for $75 \%$ of the zinc in the precipitate. This result provided direct evidence that zinc was mainly removed by coagulant flocs, and EC is an effective method for removal of heavy metal ions from wastewater. When the initial concentration of zinc is $1,000 \mathrm{mg} / \mathrm{L}$, the zinc presented in precipitation decreases to $60 \%$. It means when concentration is higher, although major part of the removed zinc presents in the precipitation, more removed zinc present in deposition, the contribution of other removal path becomes more and more significant. 

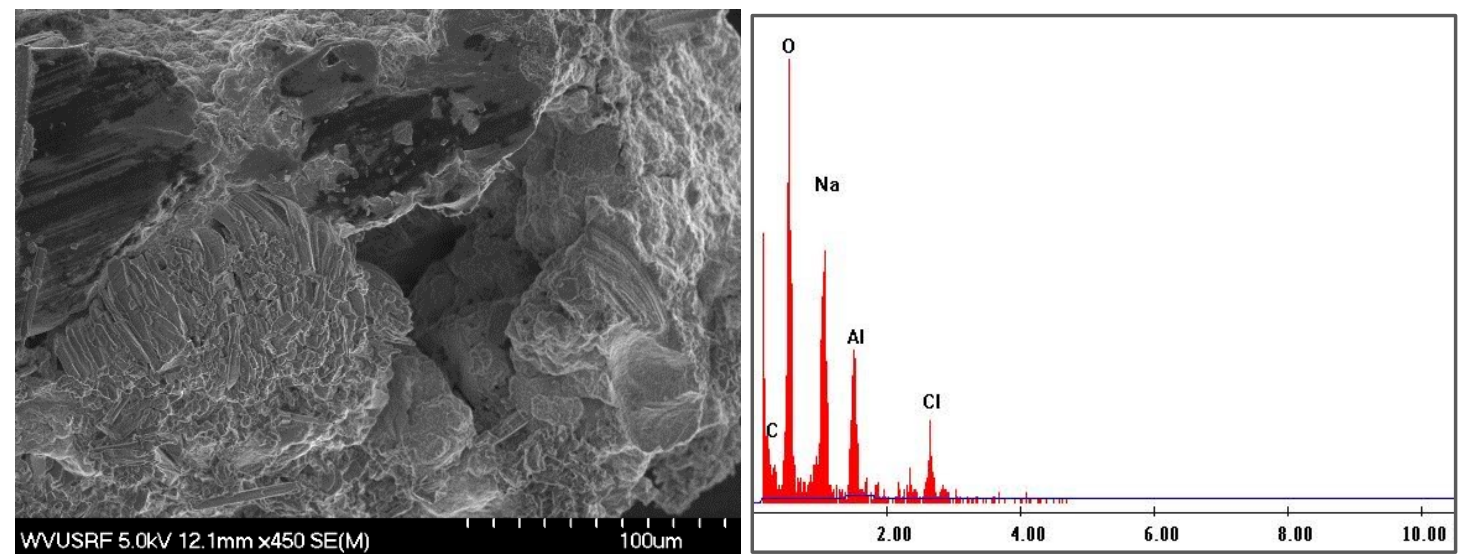

Figure 4.5 SEM and EDX results of the precipitation. Experiment carried out with zinc concentration of $500 \mathrm{mg} / \mathrm{L}$, at current density of $8.3 \mathrm{~mA} / \mathrm{cm}^{2}$ and EC time of $60 \mathrm{~min}$.

Table 4.4 ICP results of the precipitation.

\begin{tabular}{cccc}
\hline $\begin{array}{c}\text { Initial conc. } \\
(\mathrm{mg} / \mathrm{L})\end{array}$ & $\begin{array}{c}\text { Total Removal } \\
(\mathrm{mg} / \mathrm{L})\end{array}$ & $\begin{array}{c}\text { Precipitation } \\
(\mathrm{mg} / \mathrm{L})\end{array}$ & $\begin{array}{c}\text { Precipitation/Removal } \\
(\%)\end{array}$ \\
\hline 500 & 431.809 & 323.614 & 75 \\
1000 & 435.985 & 260.725 & 60 \\
\hline
\end{tabular}

The deposition was also characterized using SEM and EDX. The SEM image shows the deposition consisted of irregular micro-sheets with porous structure (Figure 4.6 left). This amorphous structure was mainly attributed to hydrogen generation at cathode surface during EC treatment (Bensadok et al. 2008). The EDS result shows the deposition was composed of O, $\mathrm{Zn}$ and Al (Figure 4.6 right). The presence of $\mathrm{Al}$ could be reasonably assigned to the adhesion of aluminum hydroxide floc on the cathode. The high amount of zinc obtained by EDX strongly evidenced the presence of zinc on the cathode as other species except the co-precipitation with aluminum hydroxide. XRD result shows the co-existence of metallic zinc, zinc oxide and zinc aluminum hydroxide compounds in the deposition (Figure 4.7). XPS results further proved the primary form of zinc is metallic state according to the characteristic peaks at 1022 and $1045 \mathrm{eV}$ (Figure 4.8). This result confirmed the presence of zinc reduction during EC process. It should be noticed that the so-called deposition was coated with precipitation, which mainly contains aluminum hydroxide 
flocs and the co-precipitated zinc. This fact explained the presence of zinc aluminum hydroxide compounds in deposition. Most of the zinc was removed by co-precipitation with aluminum hydroxide coagulants. These results show the zinc ions were removed simultaneously by precipitation with aluminum hydroxide and reduction at cathode at high initial concentration.
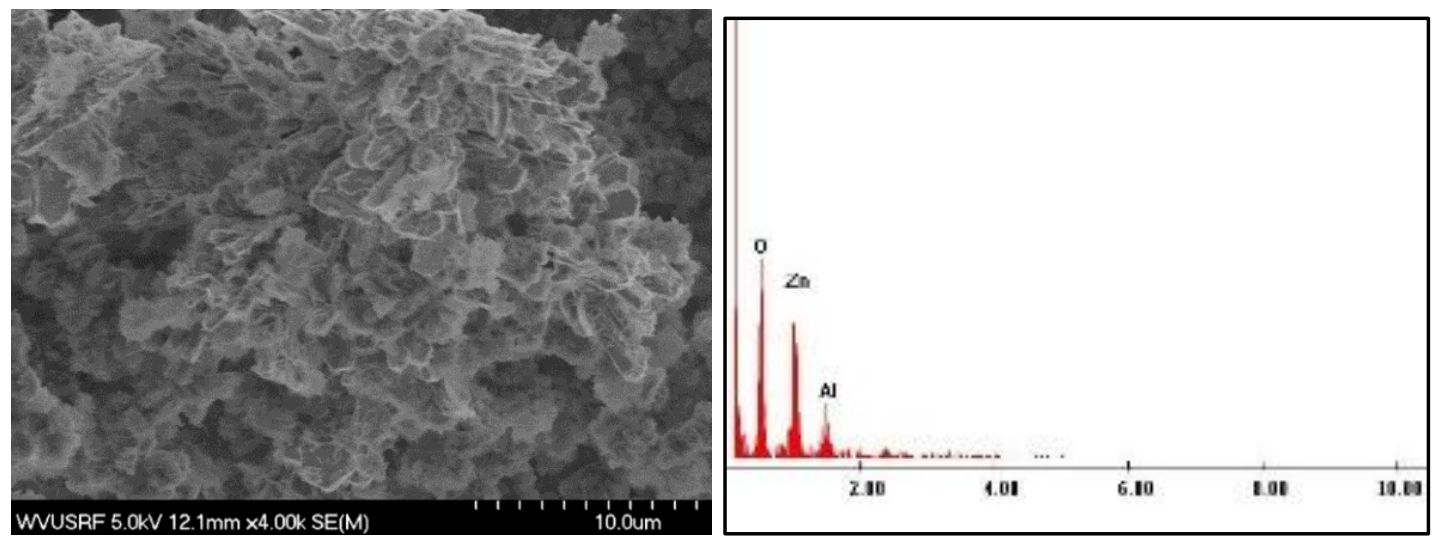

Figure 4.6 SEM and EDX results of the deposition obtained at cathode surface.

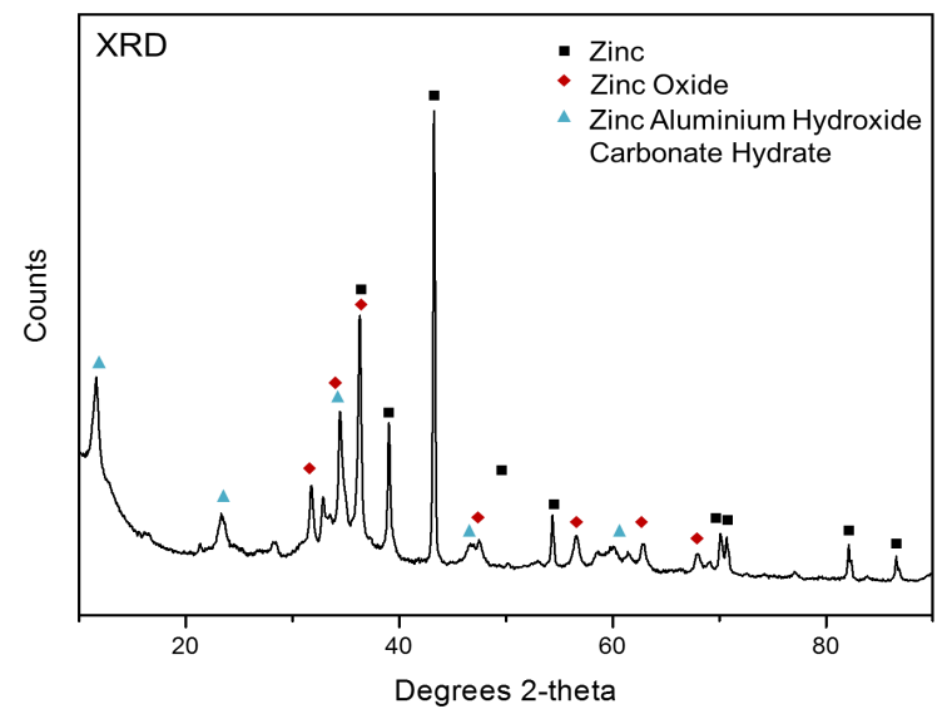

Figure 4.7 XRD spectra of the deposition. 

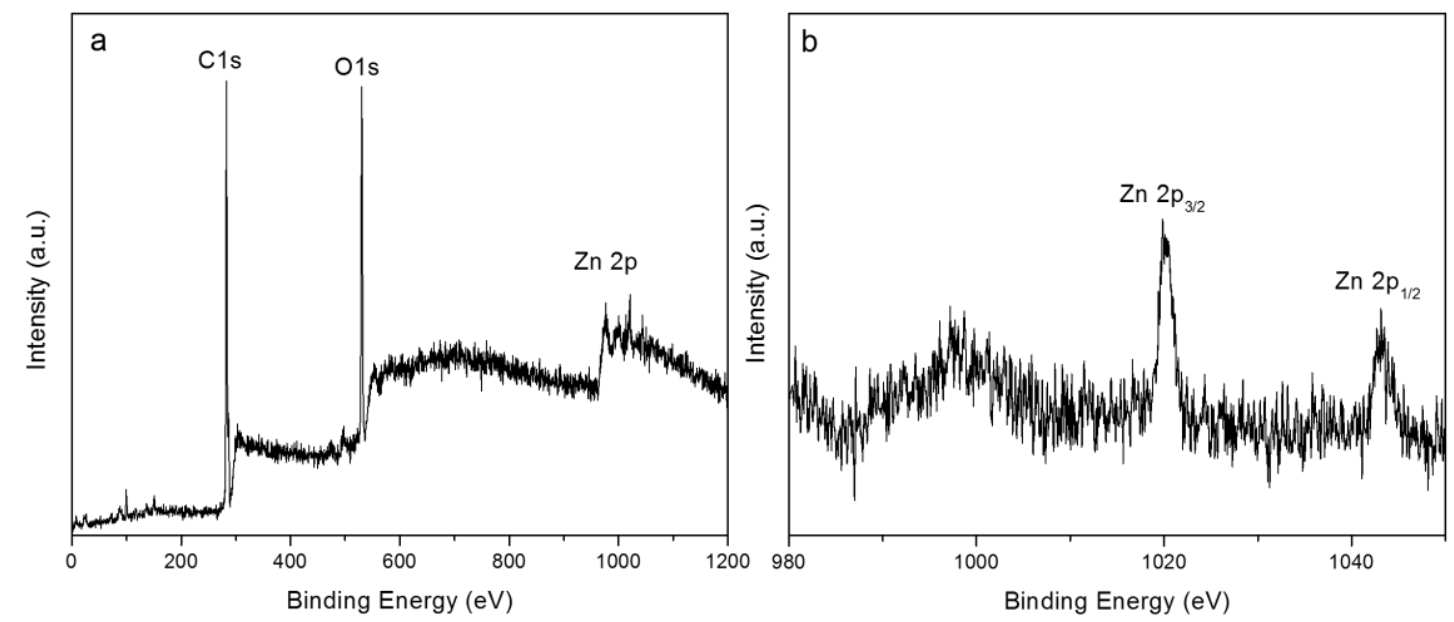

Figure 4.8 XPS spectra of the deposition: (a) full spectrum; (b) Zn 2p.

\subsubsection{Possible Removal Path of Zinc Ions by EC Treatment}

As a result of above discussion, it could be concluded that the removal of metal ions by EC attributed to the combine effect of different removal mechanisms: (a) Chemical precipitation as hydroxides form, especially at alkaline $\mathrm{pH}$ or high initial concentration of treated metals; (b) Coprecipitation with aluminum or iron hydroxide flocs ( $\mathrm{Al}$ or Fe as electrodes); (c) Adsorption by the counter charged colloidal particles formed during EC process; (d) Cathodic reduction of metal ions to metallic forms at cathode. The corresponding possible reactions when aluminum as electrodes are shown in Table 4.5 .

Table 4.5 Possible removal path for zinc ions.

Possible removal path Possible reactions

\begin{tabular}{ll}
\hline Chemical precipitation & $\mathrm{Zn}^{2+}+2 \mathrm{OH}^{-} \rightarrow \mathrm{Zn}(\mathrm{OH})_{2(\mathrm{~s})}$ \\
Co-precipitation & $\mathrm{Zn}^{2+}+\mathrm{Al}(\mathrm{OH})_{3(\mathrm{~S})} \rightarrow[$ particle $] \quad \mathrm{pH}>6.5$ \\
& $\mathrm{Zn}^{2+}+\mathrm{Monomeric} / \mathrm{Polymeric} \mathrm{Al} \rightarrow$ \\
Adsorption & $\mathrm{Al}[\mathrm{Zn} \mathrm{Monomeric/Polymeric} \mathrm{Al}]_{(\mathrm{s})} \quad \mathrm{pH}=4-6$ \\
& $\mathrm{Zn}^{2+}+2 e^{-} \rightarrow \mathrm{Zn}_{(\mathrm{s})}$
\end{tabular}


During the EC process, the aluminum hydroxide and/or polyhydroxymetallic compounds of aluminum was formed by the dissolved aluminum ions at anode and generated hydroxide ions at cathode depends on solution $\mathrm{pH}$. It served as coagulant agents and have strong adsorption for the zinc ions, which resulted in the co-precipitation of zinc ions with aluminum hydroxide flocs (Heidmann et al. 2010). The adsorption phenomenon might be attributed to the link/bridge structure formed between the aluminum colloidal particles. When metal coagulants are converted into polymers with high molecular weight and long chain, the destabilization of particles occurs due to the adsorption of reactive groups that polymer chain contains on the surface of other particles. Thereby result in the coagulation of particles (Ghernaout et al. 2011; Shen et al. 2003).

At the same time, the generated hydrogen bubbles collided with coagulated particles and brought the flocculated particles to the water surface. It effectively accelerated the separation of flocs from solution. For the model wastewater with relatively high concentration of metal ions or high $\mathrm{pH}$, it was reasonably considered that the chemical precipitation as metal hydroxides form significantly contributed the removal of metal ions (Golder et al. 2007). Even at the relative low pH of bulk solution, in which the concentration of hydroxide ions was too low for formation of thermodynamically stable hydroxide species, it was reported the metal ions could be able to precipitate with the hydroxide ions at the local zones around cathode with high $\mathrm{pH}$ (Heidmann and Calmano 2008b). When the multiple metals present in the wastewater, these metal ions can not only compete for the hydroxide ions produced at the cathode, but also compete for sorption sites at the aluminum hydroxide flocs surface.

As is known, there are two possible reactions at the cathode, zinc reduction and water reduction.

$\mathrm{Zn}^{2+}(\mathrm{aq})+2 \mathrm{e}^{-} \rightarrow \mathrm{Zn}(\mathrm{s}) \quad \mathrm{E}^{\mathrm{o}}=-0.76 \mathrm{~V} \quad(\mathrm{Eq} .26)$

$2 \mathrm{H}_{2} \mathrm{O}(\mathrm{aq})+2 \mathrm{e}^{-} \rightarrow \mathrm{H}_{2}(\mathrm{~g})+2 \mathrm{OH}^{-}(\mathrm{aq}) \quad \mathrm{E}^{\mathrm{o}}=-0.83 \mathrm{~V} \quad$ (Eq. 27)

At the standard condition $\left(\mathrm{Zn}^{2+}\right.$ concentration is $\left.1 \mathrm{~mol} / \mathrm{L}\right)$, these two reactions compete with each other due to the very close reduction potentials. The zinc reduction should be the priority because of the higher reduction potential when compared with water reduction. However, in our work, the model wastewater usually has a way lower concentration of zinc than the standard condition. So water reduction becomes priority. Well, the relative high concentration of zinc will favor the zinc 
reduction at the cathode (Al Aji et al. 2012). In our study, the experiment results showed the zinc reduction took place at the cathode, which competed for electrons with water reduction when the initial concentration of zinc is as high as $500 \mathrm{mg} / \mathrm{L}$. It worth noting that the cathodic reduction of metal ions resulted in an impermeable deposition layer at the cathode surface, preventing the effective current transport between the anode and cathode, thus induced the current efficiency.

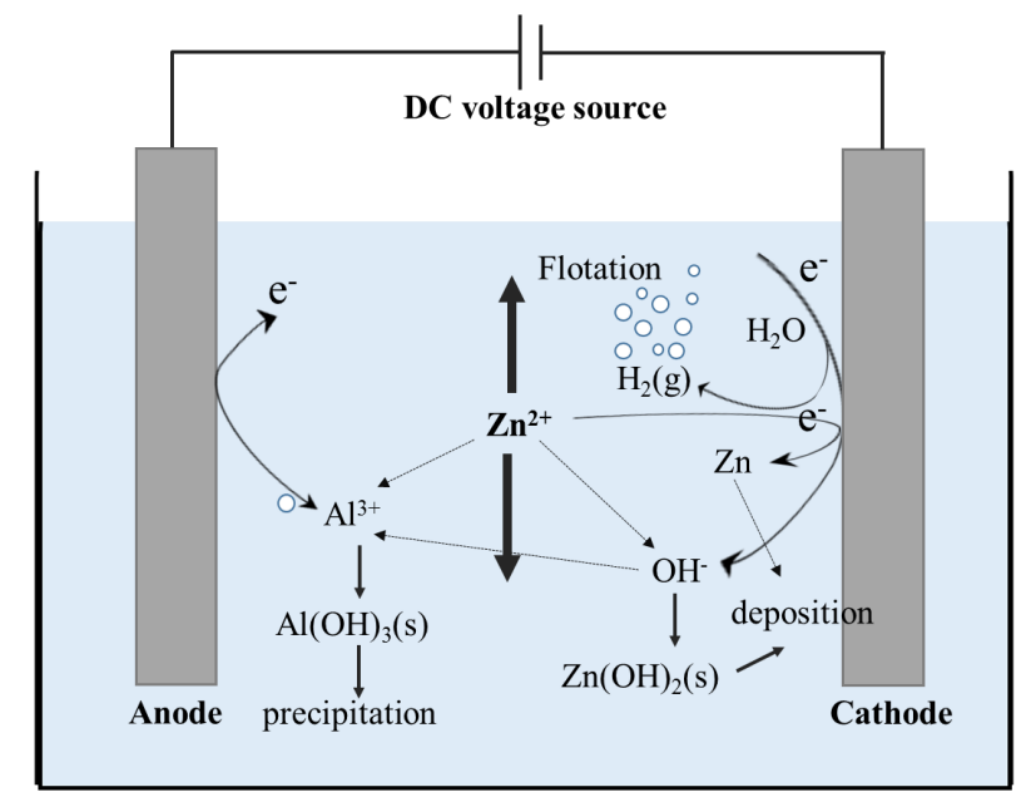

Figure 4.9 Schematic diagram of the possible removal pathways of zinc ions during EC process. 


\section{Conclusions}

This work reported the removal of metal ions with a focus on zinc from model wastewater by EC using aluminum electrodes. The results shows that the EC process is a promising method for effectively removal of zinc ions from wastewater.

The effects of parameters, such as solution conductivity, electrode spacing, initial $\mathrm{pH}$, current density and initial zinc concentration on the EC performance have been systematically investigated. It was indicated that current density strongly affects EC performance, in terms of the removal efficiency of metal ions and energy consumption. The contribution of solution conductivity on EC process might be mainly attributed to the decrease of required voltage. Moreover, it was demonstrated that the neutral $\mathrm{pH}$ is favorable for zinc removal by EC process, while the effect of electrode spacing on EC performance was not significant in this case.

The kinetic study for zinc removal was performed to describe the adsorption system during EC process in this study. The results show that the removal of zinc ions by EC process follows the first-order model with current-dependent parameters. Additionally, the removal of zinc ions fitted well with the first order model at related low initial concentration, and fitted well with the pseudofirst order model at high initial concentrations.

The EC process also was performed in mixed-contaminants wastewater which contains $\mathrm{Zn}, \mathrm{Cu}$, $\mathrm{Fe}, \mathrm{Mn}, \mathrm{Mg}, \mathrm{Ca}, \mathrm{Ba}$ and $\mathrm{Sr}$. It shows that the competitive removal of $\mathrm{Fe}, \mathrm{Cu}, \mathrm{Zn}$ and $\mathrm{Mn}$ in the mixed solution. Mg exhibited a high removal efficiency, whereas $\mathrm{Ba}$ and $\mathrm{Sr}$ could be hardly removed by EC process. The differences of removal behavior between $\mathrm{Fe}, \mathrm{Cu}, \mathrm{Zn}$ and $\mathrm{Ba} / \mathrm{Sr}$ could be attributed to the different removal mechanisms.

It could be reasonably suggested that the removal of metal ions by EC attributed to the combine effect of different removal mechanisms including chemical precipitation, co-precipitation, adsorption and cathodic reduction. It should be noted that the different removal pathways of metal ions especially occurred with high initial concentration of metal ions and alkaline $\mathrm{pH}$ medium. 


\section{References}

Agridiotis, V., Forster, C.F. and Carliell-Marquet, C., 2007. Addition of Al and Fe salts during treatment of paper mill effluents to improve activated sludge settlement characteristics. Bioresource Technology, 98(15), pp.2926-2934.

Akbal, F. and Camc1, S., 2010. Comparison of electrocoagulation and chemical coagulation for heavy metal removal. Chemical Engineering \& Technology, 33(10), pp.1655-1664.

Al Aji, B., Yavuz, Y. and Koparal, A.S., 2012. Electrocoagulation of heavy metals containing model wastewater using monopolar iron electrodes. Separation and Purification Technology, 86, pp.248-254.

Al-Shannag, M., Al-Qodah, Z., Bani-Melhem, K., Qtaishat, M.R. and Alkasrawi, M., 2015. Heavy metal ions removal from metal plating wastewater using electrocoagulation: Kinetic study and process performance. Chemical Engineering Journal, 260, pp.749-756.

Bagga, A., Chellam, S. and Clifford, D.A., 2008. Evaluation of iron chemical coagulation and electrocoagulation pretreatment for surface water microfiltration. Journal of Membrane Science, 309(1), pp.82-93.

Bazrafshan, E., Mohammadi, L., Ansari-Moghaddam, A. and Mahvi, A.H., 2015. Heavy metals removal from aqueous environments by electrocoagulation process-a systematic review. Journal of environmental health science and engineering, 13(1), p.74.

Bensadok, K.S., Benammar, S., Lapicque, F. and Nezzal, G., 2008. Electrocoagulation of cutting oil emulsions using aluminium plate electrodes. Journal of hazardous materials, 152(1), pp.423430.

Borba, C.E., Guirardello, R., Silva, E.A., Veit, M.T. and Tavares, C.R.G., 2006. Removal of nickel (II) ions from aqueous solution by biosorption in a fixed bed column: experimental and theoretical breakthrough curves. Biochemical Engineering Journal, 30(2), pp.184-191.

Canizares, P., Carmona, M., Lobato, J., Martinez, F. and Rodrigo, M.A., 2005. Electrodissolution

of aluminum electrodes in electrocoagulation processes. Industrial \& engineering chemistry research, 44(12), pp.4178-4185. 
Cañizares, P., Jiménez, C., Martínez, F., Rodrigo, M.A. and Sáez, C., 2009. The pH as a key parameter in the choice between coagulation and electrocoagulation for the treatment of wastewaters. Journal of Hazardous Materials, 163(1), pp.158-164.

Can, O.T., Kobya, M., Demirbas, E. and Bayramoglu, M., 2006. Treatment of the textile wastewater by combined electrocoagulation. Chemosphere, 62(2), pp.181-187.

Chafi, M., Gourich, B., Essadki, A.H., Vial, C. and Fabregat, A., 2011. Comparison of electrocoagulation using iron and aluminium electrodes with chemical coagulation for the removal of a highly soluble acid dye. Desalination, 281, pp.285-292.

Chen, G., Chen, X. and Yue, P.L., 2000. Electrocoagulation and electroflotation of restaurant wastewater. Journal of environmental engineering, 126(9), pp.858-863.

Chen, G., 2004. Electrochemical technologies in wastewater treatment. Separation and purification Technology, 38(1), pp.11-41.

De Mello Ferreira, A., Marchesiello, M. and Thivel, P.X., 2013. Removal of copper, zinc and nickel present in natural water containing $\mathrm{Ca} 2+$ and ions by electrocoagulation. Separation and Purification Technology, 107, pp.109-117.

Duan, J. and Gregory, J., 2003. Coagulation by hydrolysing metal salts. Advances in colloid and interface science, 100, pp.475-502.

Emamjomeh, M.M. and Sivakumar, M., 2009. Review of pollutants removed by electrocoagulation and electrocoagulation/flotation processes. Journal of environmental management, 90(5), pp.1663-1679.

Gao, P., Chen, X., Shen, F. and Chen, G., 2005. Removal of chromium (VI) from wastewater by combined electrocoagulation-electroflotation without a filter. Separation and purification technology, 43(2), pp.117-123.

Ghernaout, D., Naceur, M.W. and Ghernaout, B., 2011. A review of electrocoagulation as a promising coagulation process for improved organic and inorganic matters removal by electrophoresis and electroflotation. Desalination and Water Treatment, 28(1-3), pp.287-320. 
Golder, A.K., Samanta, A.N. and Ray, S., 2007. Removal of $\mathrm{Cr}^{3+}$ by electrocoagulation with multiple electrodes: bipolar and monopolar configurations. Journal of Hazardous Materials, 141(3), pp.653-661.

Hakizimana, J.N., Gourich, B., Chafi, M., Stiriba, Y., Vial, C., Drogui, P. and Naja, J., 2017. Electrocoagulation process in water treatment: A review of electrocoagulation modeling approaches. Desalination, 404, pp.1-21.

Heidmann, I. and Calmano, W., 2008a. Removal of Cr (VI) from model wastewaters by electrocoagulation with Fe electrodes. Separation and Purification Technology, 61(1), pp.15-21.

Heidmann, I. and Calmano, W., 2008b. Removal of Zn (II), Cu (II), Ni (II), Ag (I) and Cr (VI) present in aqueous solutions by aluminium electrocoagulation. Journal of Hazardous Materials, 152(3), pp.934-941.

Heidmann, I. and Calmano, W., 2010. Removal of $\mathrm{Ni}, \mathrm{Cu}$ and $\mathrm{Cr}$ from a galvanic wastewater in an electrocoagulation system with Fe-and Al-electrodes. Separation and Purification Technology, 71(3), pp.308-314.

Hernández, M.C., Barletta, L., Dogliotti, M.B., Russo, N., Fino, D. and Spinelli, P., 2012. Heavy metal removal by means of electrocoagulation using aluminum electrodes for drinking water purification. Journal of Applied Electrochemistry, 42(9), pp.809-817.

Holt, P.K., Barton, G.W., Wark, M. and Mitchell, C.A., 2002. A quantitative comparison between chemical dosing and electrocoagulation. Colloids and Surfaces A: Physicochemical and Engineering Aspects, 211(2), pp.233-248.

Holt, P.K., Barton, G.W . and Mitchell, C.A., 2005. The future for electrocoagulation as a localised water treatment technology. Chemosphere, 59(3), pp.355-367.

Jiménez, C., Sáez, C., Martínez, F., Cañizares, P. and Rodrigo, M.A., 2012. Electrochemical dosing of iron and aluminum in continuous processes: a key step to explain electro-coagulation processes. Separation and purification technology, 98, pp.102-108.

Kamaraj, R. and Vasudevan, S., 2015. Evaluation of electrocoagulation process for the removal of strontium and cesium from aqueous solution. Chemical engineering research and design, 93, pp.522-530. 
Kurniawan, T.A., Chan, G.Y., Lo, W.H. and Babel, S., 2006. Physico-chemical treatment techniques for wastewater laden with heavy metals. Chemical engineering journal, 118(1), pp.8398.

Lakshmanan, D., Clifford, D.A. and Samanta, G., 2009. Ferrous and ferric ion generation during iron electrocoagulation. Environmental science \& technology, 43(10), pp.3853-3859.

Li, S., Wang, W., Liang, F. and Zhang, W.X., 2017. Heavy metal removal using nanoscale zerovalent iron (nZVI): theory and application. Journal of hazardous materials, 322, pp.163-171.

Martínez-Huitle, C.A. and Brillas, E., 2009. Decontamination of wastewaters containing synthetic organic dyes by electrochemical methods: a general review. Applied Catalysis B: Environmental, 87(3), pp.105-145.

Mollah, M.Y.A., Schennach, R., Parga, J.R. and Cocke, D.L., 2001. Electrocoagulation (EC)— science and applications. Journal of hazardous materials, 84(1), pp.29-41.

Mollah, M.Y., Morkovsky, P., Gomes, J.A., Kesmez, M., Parga, J. and Cocke, D.L., 2004. Fundamentals, present and future perspectives of electrocoagulation. Journal of hazardous materials, 114(1), pp.199-210.

Mouedhen, G., Feki, M., Wery, M.D.P. and Ayedi, H.F., 2008. Behavior of aluminum electrodes in electrocoagulation process. Journal of hazardous materials, 150(1), pp.124-135.

Moussa, D.T., El-Naas, M.H., Nasser, M. and Al-Marri, M.J., 2017. A comprehensive review of electrocoagulation for water treatment: Potentials and challenges. Journal of environmental management, 186, pp.24-41.

Mo, X., Yang, Z.H., Xu, H.Y., Zeng, G.M., Huang, J., Yang, X., Song, P.P. and Wang, L.K., 2015. Combination of cathodic reduction with adsorption for accelerated removal of $\mathrm{Cr}$ (VI) through reticulated vitreous carbon electrodes modified with sulfuric acid-glycine co-doped polyaniline. Journal of hazardous materials, 286, pp.493-502.

Murthy, Z.V.P. and Parmar, S., 2011. Removal of strontium by electrocoagulation using stainless steel and aluminum electrodes. Desalination, 282, pp.63-67. 
Nanseu-Njiki, C.P., Tchamango, S.R., Ngom, P.C., Darchen, A. and Ngameni, E., 2009. Mercury (II) removal from water by electrocoagulation using aluminium and iron electrodes. Journal of Hazardous Materials, 168(2), pp.1430-1436.

Oyaro, N., Ogendi, J., Murago, E.N. and Gitonga, E., 2007. The contents of $\mathrm{Pb}, \mathrm{Cu}, \mathrm{Zn}$ and $\mathrm{Cd}$ in meat in nairobi, Kenya.

Paulino, A.T., Minasse, F.A., Guilherme, M.R., Reis, A.V., Muniz, E.C. and Nozaki, J., 2006. Novel adsorbent based on silkworm chrysalides for removal of heavy metals from wastewaters. Journal of colloid and interface science, 301(2), pp.479-487.

Picard, T., Cathalifaud-Feuillade, G., Mazet, M. and Vandensteendam, C., 2000. Cathodic dissolution in the electrocoagulation process using aluminium electrodes. Journal of Environmental Monitoring, 2(1), pp.77-80.

Rudnicki, P., Hubicki, Z. and Kołodyńska, D., 2014. Evaluation of heavy metal ions removal from acidic waste water streams. Chemical Engineering Journal, 252, pp.362-373.

Sasson, M.B., Calmano, W. and Adin, A., 2009. Iron-oxidation processes in an electroflocculation (electrocoagulation) cell. Journal of hazardous materials, 171(1), pp.704-709.

Shen, F., Chen, X., Gao, P. and Chen, G., 2003. Electrochemical removal of fluoride ions from industrial wastewater. Chemical Engineering Science, 58(3), pp.987-993.

Sun, L., Miznikov, E., Wang, L. and Adin, A., 2009. Nickel removal from wastewater by electroflocculation-filtration hybridization. Desalination, 249(2), pp.832-836.

Vasudevan, S., Lakshmi, J. and Sozhan, G., 2011. Effects of alternating and direct current in electrocoagulation process on the removal of cadmium from water. Journal of hazardous materials, 192(1), pp.26-34.

Vepsäläinen, M., 2012. Electrocoagulation in the treatment of industrial waters and wastewaters. VTT Technical Research Centre of Finland.

Zhu, B., Clifford, D.A. and Chellam, S., 2005. Comparison of electrocoagulation and chemical coagulation pretreatment for enhanced virus removal using microfiltration membranes. Water research, 39(13), pp.3098-3108. 